\title{
3 Research Square

\section{Characterizing the Deep Pumping-induced Subsidence Against Metro Tunnel Using Vertically Distributed Fiber-Optic Sensing}

\section{Yunxiao Xin}

Nanjing University

Xiaozhao Li ( $\sim$ hapoaaa@foxmail.com )

Nanjing University https://orcid.org/0000-0002-7049-8989

Wei Zhang

Nanjing University

Qi Wang

Geo-engineering Investigation Institute of Jiangsu Province

\section{Research Article}

Keywords: Deep pumping, Differential settlement, Metro tunnel, Distributed fiber-optic sensing (DFOS), Space-time matrix

Posted Date: March 17th, 2021

DOI: https://doi.org/10.21203/rs.3.rs-168411/v1

License: (c) (i) This work is licensed under a Creative Commons Attribution 4.0 International License. Read Full License

Version of Record: A version of this preprint was published at Environmental Earth Sciences on November 1st, 2021. See the published version at https://doi.org/10.1007/s12665-021-09990-z. 


\section{Characterizing the deep pumping-induced subsidence against metro tunnel}

\section{using vertically distributed fiber-optic sensing}

Xin Yunxiao $^{1}$, Li Xiaozhao ${ }^{1 *}$, Zhang $\mathrm{Wei}^{1}$, Wang $\mathrm{Qi}^{2}$

1. School of Earth Sciences and Engineering, Nanjing University, 163 Xianlin Avenue, Nanjing, 210023, China

2. Geo-engineering Investigation Institution of Jiangsu Province, 17 Meilin Street, Nanjing, 211101, China

\section{Corresponding Author:}

Li Xiaozhao

Professor, Ph.D. supervisor, School of Earth Sciences and Engineering, Nanjing University,

No. 163 Xianlin Avenue, Nanjing, 210023, PR China

Email: lixz@nju.edu.cn 
1 Abstract: Continuous pumping of groundwater will induce uneven ground settlement, which

2 may adversely affect the nearby metro tunnels. In this paper, taking Nantong Metro Line 1

3 crossing Nantong Port Water Plant as an example, the surface level measurement and

4 subsurface deformation monitoring using vertically distributed fiber-optic sensing are

5 implemented to acquire the surface and subsurface settlement of emergency water supply

6 conditions. The fiber optic cable vertically buried in the constant-temperature layer is used to

7 measure the subsurface strain field and deduce the deformation amount of each stratum. The

8 monitoring results show that, during the pumping, the deformation of the aquifer and ground

9 surface is linearly compressed with time; after the pumping, the ground surface continues to

10 settle linearly at a slower rate for about 50 days, followed by a slow linear rebound, and the

11 aquifer is logarithmically rebounded. In addition, deep pumping causes the deformation of the

12 aquifers to be much greater than the surface settlement; the surface settlement lags behind the

13 settlement of the aquifer by 1 to 2 months; the surface rebound recovery also exhibits a similar

14 delay. Fitting models were derived to predict the maximum settlement and curvature radius of

15 the site, which indicates that the adverse effects against the metro tunnel are not negligible once

16 the continuous pumping exceeds 15 days. Those insights can be referred by the practitioners

17 for the control of urban subsidence.

18 Keywords: Deep pumping; Differential settlement; Metro tunnel; Distributed fiber-optic

19 sensing (DFOS); Space-time matrix. 


\section{INTRODUCTION}

22 Ground subsidence is a hazardous environmental geology issue which not only reduces

23 stratum elevations but also yields damage to buildings and infrastructure (Herrera-García et al.,

24 2021; Pacheco-Martínez et al., 2013). Moreover, for metro tunnels, one of the most common

25 linear underground infrastructures in cities, the longitudinal differential deformation induced

26 by ground subsidence can lower their safety, durability, and waterproof performances (Peng et

27 al., 2017; Wang et al., 2016). The variation of the groundwater level induced by human activities is a major cause of differential subsidence in urban areas (Edalat et al., 2020; Xu et

al., 2016b; Xue et al., 2005). Particularly, for those cities which have to withdraw underground water as the water supply, long-term pumping activities in the water source area might induce serious subsidence problems (Chai et al., 2004; Othman and Abotalib, 2019).

32 Given the differential settlement, former studies mainly focused on its impacts on surface buildings. However, recent studies of ground subsidence against metro tunnels have revealed that, compared with the negative impacts imposed by the settlement of ground surface, those induced by the subsurface deformation are more significant for underground infrastructures

36 (Shen et al., 2014). Zheng et al. (2014) studied the stratified settlement caused by the extraction of confined water using field tests and found that the deformation of phreatic layers is less than that of the confined aquifer layers, which was other than the acknowledged settlement law caused by dewatering of ground surface. Note a growing consensus has suggested that ground

40 subsidence occurs lagging behind the pumping activity (Kearns et al., 2015), and the duration 41 of land subsidence induced by deep pumping is longer than that by surface pumping (Cui and 
42 Jia, 2018). However, current theoretical models of the pumping-induced settlement remain

43 unavailable to fully characterize the abovementioned influencing factors (Budhu and Adiyaman,

44 2010; Wang et al., 2018; Xu et al., 2012; Zhang et al., 2017; Zhou et al., 2017). Therefore, concerning extracting deep groundwater scenarios, current models still have to be deliberately calibrated by the field measurements (Shen and $\mathrm{Xu}, 2011$; Xu et al., 2016a). al., 2006), such as leveling (Abidin et al., 2001), GPS (Baldi et al., 2009; Choudhury et al., 2018; Hu et al., 2006; Mousavi et al., 2001), InSAR (Calderhead et al., 2011; Motagh et al., 2017), and their combinations (Galloway and Burbey, 2011; Saleh and Becker, 2018). Note all those measures cannot acquire layered subsidence measurements; even the layered marks can acquire, in that the layered settlement meters are fixed-point arranged, the discrete subsidence measurements cannot finely characterize the subsurface deformation field (Jiang et al., 2016).

54 The distributed fiber-optic sensing (DFOS), a novel monitoring technique, can obtain the strain field along the sensing cable. Although the DFOS has been employed to monitor the subsurface deformation field of Shengze, an abnormal post-dewatering subsiding area in Suzhou of China

57 (Gu et al., 2018; Zhang et al., 2018), however, few works have been documented to use DFOS to monitor the variation process of the subsurface deformation field during a rapid pumping, no mention assess its negative impacts against metro tunnels.

60 In this paper, taking a groundwater plant near Nantong Port, Jiangsu Province of China, as 61 an example, a test of deep multi-well dewatering was implemented to verify the applicability and feasibility of the DFOS technique to monitor the variation of the subsurface deformation 
63 field. Feature extraction on the DFOS measurements was also performed to assess the impacts

64 of subsurface settlement against the metro tunnel. Fitting equations were deduced to shed light

65 on the evolutionary trend of the surface and subsurface deformation field during and after the

66 pumping, which can be used to predict its long-term impacts against the metro tunnel.

\section{PRINCIPLE OF DISTRIBUTED FIBER-OPTIC SENSING (DFOS)}

A variety of DFOSs can be used for strain field monitoring (Zhang et al., 2014). Typically, the Brillouin optical time-domain reflectometer (BOTDR) is used in this paper. The principle of the BOTDR is based on the change in the scattered light caused by nonlinear interactions between the incident light and the phonons which are thermally excited within the light propagation medium. When occurring in an optical fiber, the backscattered light experiences a frequency shift (the Brillouin frequency), which is dependent on the temperature and strain environment of the fiber (Wu et al., 2015). Compared with other scattered lights, a substantial advantage of Brillouin scattering is that its frequency shift caused by temperature is only $0.002 \% /{ }^{\circ} \mathrm{C}$, which is much smaller than that caused by strain. Therefore, while measuring the

Brillouin frequency shift induced by strain, the influence of the temperature on the Brillouin frequency shift can be neglected if the changes of temperature are within $2{ }^{\circ} \mathrm{C}$. The relationship between the Brillouin frequency shift and the strain of optical fiber yields:

$$
v_{B}(\varepsilon)=v_{B}(0)+\frac{\mathrm{d} v_{B}(\varepsilon)}{\mathrm{d} \varepsilon} \varepsilon
$$

where $v_{B}(\varepsilon)$ is the Brillouin frequency against strain $\varepsilon, v_{B}(0)$ is the Brillouin frequency shift without stain, $\mathrm{d} v_{B}(\varepsilon) / \mathrm{d} \varepsilon$ is the strain coefficient, and the proportional coefficient of strain, at a wavelength of $1.55 \mu \mathrm{m}$, is approximately $0.5 \mathrm{GHz} / \%$. 
85 Given the monitoring scenario of land subsidence, the deformation field along the sensing 86 optical cable caused by soil compression or rebound at depth $h$ can be calculated in accordance

87 with the measured strain, which yields:

$$
\Delta d=\int_{h_{1}}^{h_{2}} \varepsilon(h) \mathrm{d} h
$$

89 In this paper, a metal-reinforced single-core cable (MRC) was used to measure the

90 subsurface deformation, whose structure is shown in Fig. 1. The MRC, which can effectively

91 protect the optical fibers with several metal reinforcers, has good coupling and uniformity with

92 soil due to the screw structure of the sensor surface (Gu et al., 2018), the type of MRC in this test is NZS-DSS-C02. distributions along with the underground depth, the measurements ought to be organized in the

Fig. 1. The structure of a metal-reinforced single-core cable (MRC).

Note DFOS acquires mass strain measurements; to efficiently extract the morphological form of a space-time matrix $\boldsymbol{B}$ (Sun et al., 2014). Given that the total number of sampling points

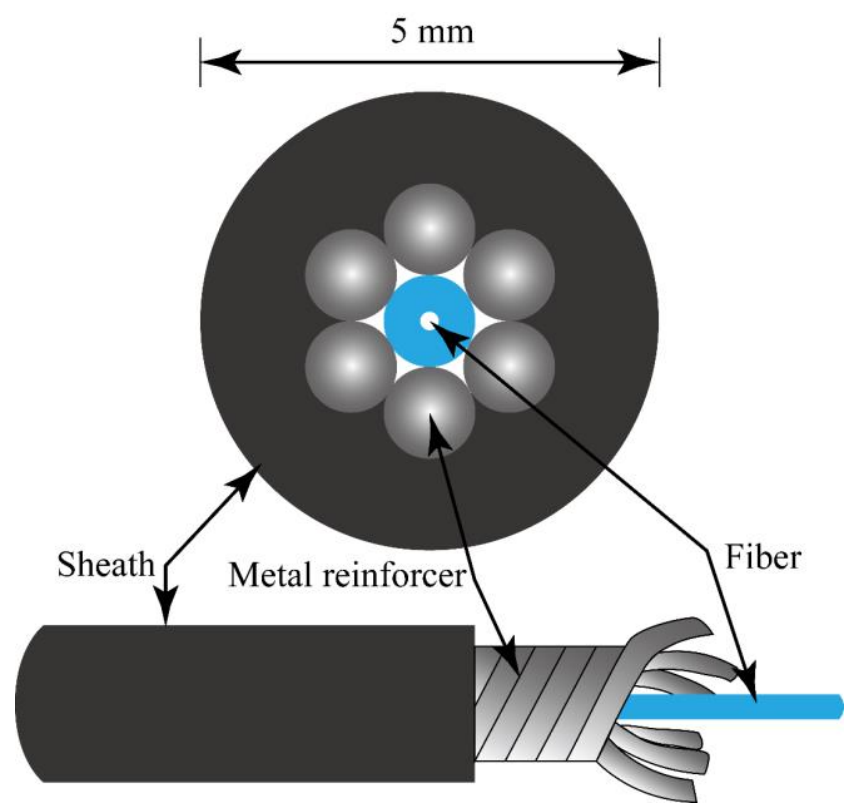


99 along the optical fiber is $n$ and the total number of sampling times is $m, \boldsymbol{B}$ is a two-dimensional

100 matrix with $n$ rows and $m$ columns, which yields:

101

$$
\begin{aligned}
& \begin{array}{llllll}
\hat{e}_{0} \varepsilon_{00} & \varepsilon_{10} & \mathrm{~L} & \varepsilon_{j 0} & \mathrm{~L} & \varepsilon_{m 0} \text { ù ù }
\end{array}
\end{aligned}
$$

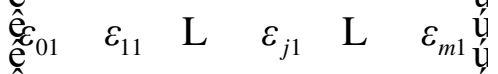

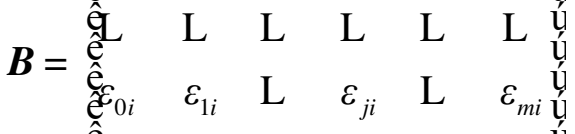

$$
\begin{aligned}
& \begin{array}{llllll}
\hat{e} & \mathrm{e} & \mathrm{L} & \mathrm{L} & \mathrm{L} & \mathrm{L} \\
\mathrm{e} \\
\mathrm{e}
\end{array}
\end{aligned}
$$

102 where the element $\varepsilon_{i j}$ is the measurements of the strain field on the measuring point with

103 different depth $i$ at sampling time $j$.

104 Now that using the DFOS for subsidence monitoring, the submatrix $\boldsymbol{B}_{s}$ of the space-time

105 matrix $\boldsymbol{B}$ is usually extracted to characterize the local distribution of stratum deformation field,

106 which yields:

107

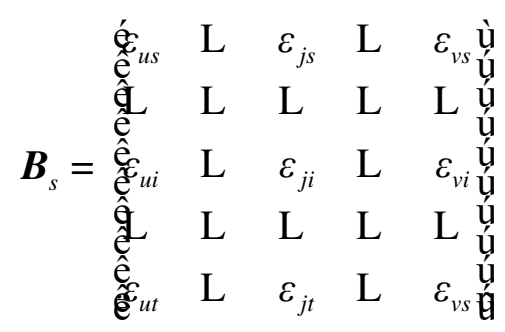

108 where the time interval of sampling points of the submatrix $\boldsymbol{B}_{s}$ is $[u, v]$, and that of the sampling

109 depth interval is $[s, t]$. The submatrix $\boldsymbol{B}_{s}$ can also be represented as a column vector group,

110 which yields:

111

$$
\boldsymbol{B}_{s}=\mathrm{e}_{\varepsilon}, \boldsymbol{E}_{u+1} \mathrm{~L} \boldsymbol{E}_{j} \mathrm{~L} \boldsymbol{E}_{v} \text { ไ̀̀ }
$$

112 where

113

$$
\boldsymbol{E}_{j}=\dot{e}_{j s}, \varepsilon_{j, s+1} \mathrm{~L} \varepsilon_{j i} \mathrm{~L} \varepsilon_{j t}^{\text {畜 }}
$$


114 The column vector $\boldsymbol{E}_{j}$ represents the strain vector acquired by the DFOS at the depth range $[s$,

$115 t$ at sampling time $j$. The column vector $\boldsymbol{E}_{j}$ at a certain time is substituted into Eq. (2) to obtain

116 the ground deformation $\Delta d$ at a specific depth range $[s, t]$, which yields:

$$
\mathrm{D} d_{s t}=\grave{\mathrm{O}}_{h_{s}}^{h_{t}} \varepsilon_{j i} \mathrm{~d} h_{i}
$$

118 where $h_{i}$ is the length of a certain measured micro-element section of the DFOS in the formation.

119 3. Pumping test

120

\subsection{Conditions of engineering geology and hydrogeology}

121 Nantong, a coastal city in eastern China, has planned to build four metro lines. Among those,

122 the planned section between the Jianghai Avenue Station and the Bus Station of Metro Line 1

123 will travel beneath the emergency water source of the Nantong Port Water Plant. The tunnel

124 has a circular section with a burial depth of $21 \mathrm{~m}$. The lining structure has an inner diameter of

$1255.5 \mathrm{~m}$ and a thickness of $0.35 \mathrm{~m}$. In accordance with the relevant specifications (Gao et al.,

126 2010), the cumulative settlement of the layer where the tunnel is located should not exceed 20

$127 \mathrm{~mm}$, and the curvature radius of the longitudinal deformation curve is not less than 15,000 $\mathrm{m}$.

128 Given the emergency water supply, a large amount of groundwater will be extracted from the

129 aquifer. This may induce subsidence within the overlying strata, which might in turn pose some

130 threats to the operational safety of the metro. This paper characterizes the adverse impacts of

131 emergency pumping on the metro tunnel by monitoring the subsurface deformation field

132 induced by a test of multi-well dewatering. 
133 Nantong is located in the alluvial plain of the Yangtze River Delta, widely covered by the

134 Quaternary strata. The thickness of the strata ranges from 200 to $360 \mathrm{~m}$, which is composed of

135 a set of multiple sedimentary cycles with alternating sand and clay layers. The pumping test

136 was performed on the south bank of the estuary of the Tonglv Canal into the Yangtze River, as

137 shown in Fig. 2. The geographic location of the testing site is $32^{\circ} 00^{\prime} 55^{\prime \prime} \sim 32^{\circ} 01^{\prime} 16^{\prime \prime}$ North

138 latitude and $120^{\circ} 49^{\prime} 11^{\prime \prime} \sim 120^{\circ} 49^{\prime} 33^{\prime \prime}$ East longitude, with a site altitude of about $4.0 \mathrm{~m}$. Nantong

139 has a humid subtropical monsoon climate with an annual average temperature of $16{ }^{\circ} \mathrm{C}$,

140 precipitation of $1036 \mathrm{~mm}$, and evaporation of $1392 \mathrm{~mm}$.

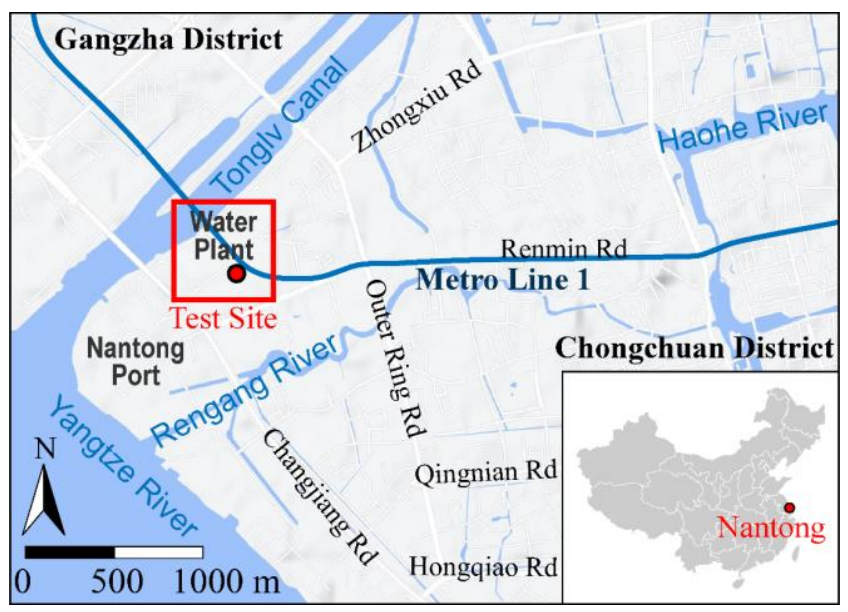

142

Fig. 2. Location of the test site.

143 Table 1 lists the physical and mechanical parameters of the strata of the test site according

144 to the preliminary investigation works. As seen from the table, the strata are mainly composed

145 of sandy soils mixed with silty clayey soils. Among those, the silt layer at a depth of $50 \mathrm{~m}$

146 attains a great amount of water content, as well as a small compression modulus. The

147 permeability varies between the silty clay and silty sand interlayers within both ranges of 120

148 to $150 \mathrm{~m}$ and 180 to $190 \mathrm{~m}$. Note both interlayers might impede the transit of groundwater, 
149 which causes the inconsistency between the deformation fields of the subsurface and the ground 150 surface.

Table 1. Physical and mechanical parameters of soils.

\begin{tabular}{cccccccc}
\hline Soil layer & $\begin{array}{c}\text { Depth } \\
(\mathrm{m})\end{array}$ & $\begin{array}{c}w \\
(\%)\end{array}$ & $G_{s}$ & $\begin{array}{c}\rho \\
\left(\mathrm{kN} / \mathrm{m}^{3}\right)\end{array}$ & $\begin{array}{c}E_{s} \\
(\mathrm{MPa})\end{array}$ & $\begin{array}{c}c \\
(\mathrm{kPa})\end{array}$ & $\begin{array}{c}\varphi \\
\left({ }^{\circ}\right)\end{array}$ \\
\hline Filling & 5 & 28.2 & 2.7 & 18.2 & 9.1 & 14.1 & 17.6 \\
Silty sand & 30.3 & 22.5 & 2.7 & 19.6 & 13.9 & 6.4 & 26.8 \\
Silty clay & 49.5 & 32.7 & 2.2 & 15.7 & 7.8 & 15.4 & 19.8 \\
Medium sand & 116.5 & 18.3 & 2.7 & 19.6 & 16.4 & 2.4 & 32.7 \\
Silty clay & 133.0 & 23.8 & 2.7 & 20.0 & 10.9 & 43.6 & 20.6 \\
Fine sand & 146.5 & 20.7 & 2.7 & 19.4 & 13.5 & 3.0 & 32.2 \\
Clay & 181.0 & 22.6 & 2.7 & 19.8 & 11.4 & 110.4 & 22.7 \\
Fine sand & 187.9 & 21.8 & 2.3 & 17.3 & 21.3 & 16.9 & 31.7 \\
Silty clay & 193.2 & 24.8 & 2.3 & 17.0 & 14.2 & 3.3 & 31.2 \\
Medium sand & 225.5 & 19.8 & 2.7 & 19.0 & 11.8 & 3.4 & 31.5 \\
Clay & 230.0 & 20.7 & 2.8 & 20.8 & 14.4 & 116.1 & 20.3 \\
\hline
\end{tabular}

152 The groundwater is mainly pore water, mostly stored in sand layers. In accordance with the

153 storage condition, the groundwater can be divided into five aquifer groups from top to bottom,

154 namely, the phreatic aquifer (PA), the 1st confined aquifer (CA1), the 2nd confined aquifer

155 (CA2), the 3rd confined aquifer (CA3) and the 4th confined aquifer (CA4). Note that only CA4

156 is not included in this test.

157 The PA consists of the silty clay, silty sand, and fine sand of the Yangtze Delta phase of

158 Holocene $\left(\mathrm{Q}_{\mathrm{h}}\right)$, buried upon a shallow depth of $50 \mathrm{~m}$. The depth of the water level, seasonally

159 varying from 1 to $3 \mathrm{~m}$, is affected by the atmospheric precipitation and surface runoff. The layer

160 of PA is characterized by the coarse particles in the upper and lower sections and fine particles

161 in the middle section along the vertical direction; some sections of the lower aquifer are 
162 connected to CA1. The dewatering amount of a single-well is about $10 \sim 20 \mathrm{~m}^{3} / \mathrm{d}$, with poor 163 water quality and thus few exploitations.

164 The CA1 consists of alluvial and marine loose sands of the Upper Pleistocene $\left(\mathrm{Q}_{\mathrm{p} 3}\right)$, with a 165 burial depth ranging from 50 to $110 \mathrm{~m}$. The lithology of the aquifer mainly consists of pebbles, 166 gravel, coarse sand, medium sand, fine sand, and silty sand; those soil particles, from coarse to 167 fine, are vertically distributed from bottom to top. The aquifer has high permeability and thus 168 enough groundwater supply, which is closely connected to the upper aquifer PA and lower 169 aquifer CA2. The dewatering amount of a single-well is about $2000 \sim 3000 \mathrm{~m}^{3} / \mathrm{d}$, also with poor 170 water quality.

171 The CA2 consists of the fine sand and silty sand layers of the fluvial and estuarine 172 sedimentary of Middle Pleistocene $\left(\mathrm{Q}_{\mathrm{p} 2}\right)$, buried from 130 to $150 \mathrm{~m}$. Note the water barrier 173 between CA1 and CA2 is partially missing. The dewatering amount of a single-well is about $174300 \sim 3000 \mathrm{~m}^{3} / \mathrm{d}$, still with poor water quality.

175 Aquifer CA3 consists of gravelly medium sand, fine sand, and locally gravelly cobble of 176 river-lake sedimentary of the Lower Pleistocene $\left(\mathrm{Q}_{\mathrm{p} 1}\right)$, whose buried depth ranges from 180 to $177240 \mathrm{~m}$, with an uneven thickness ranging from 20 to $100 \mathrm{~m}$. The dewatering amount of a single-

178 well is generally over $2000 \mathrm{~m}^{3} / \mathrm{d}$. Both the quality and quantity of the groundwater are good 179 and rich, which makes CA3 the main exploited freshwater aquifer of Nantong city. Note that 180 in this test, the groundwater is extracted from aquifer CA3, with a well depth of $225 \mathrm{~m}$. 


\subsection{Test layout and schedule}

182 Fifteen pumping wells, labeled from W1 to W15, of the Nantong Port Water Plant near the

183 metro line 1 were selected for this test. All wells were pumped at a rate of $80 \mathrm{t} / \mathrm{h}$ under the

184 emergency water supply conditions, from August 9 to 15, 2018. The layout of the pumping

185 wells and monitoring points is shown in Fig. 3. Two well groups exist in the test site, namely

186 the south well group, W1 to W7, located near the water plant on the southern side, and the north

187 well group, W8 to W15, at the river bank on the northern side. In addition, 23 monitoring points

188 of ground surface settlement, labeled as S1 to S23, were deployed near the metro line and both

189 pumping well groups.

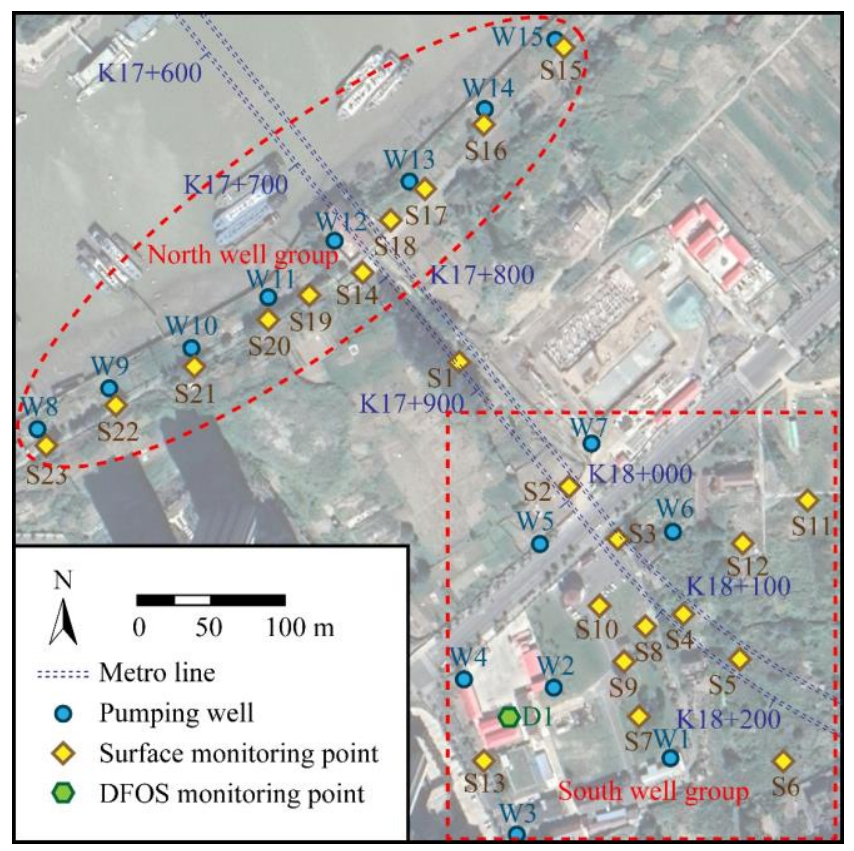

191

Fig. 3. Test layout.

192 Given the subsurface deformation field might vary from that of the surface ground, a

193 borehole (D1), with a depth of $230 \mathrm{~m}$ and a diameter of $129 \mathrm{~mm}$, was deliberately drilled and

194 a metal-reinforced single-core cable (MRC) was laid inside to measure the vertical subsurface 

end of the MRC was connected to a BOTDR interrogator, which can process and record the

197 strain field data along with the optical cable. The parameters of the interrogator are listed in Table 2. Before the pumping, the borehole was backfilled with special fillings to make the MRC fully couple with the surrounding soils. To synchronize the deformation of fiber with the subsurface strata, fine sand-clay soft aggregate, similar to the site strata, was used for the backfill material in the borehole. The deformation modulus of the backfill soil was adjusted

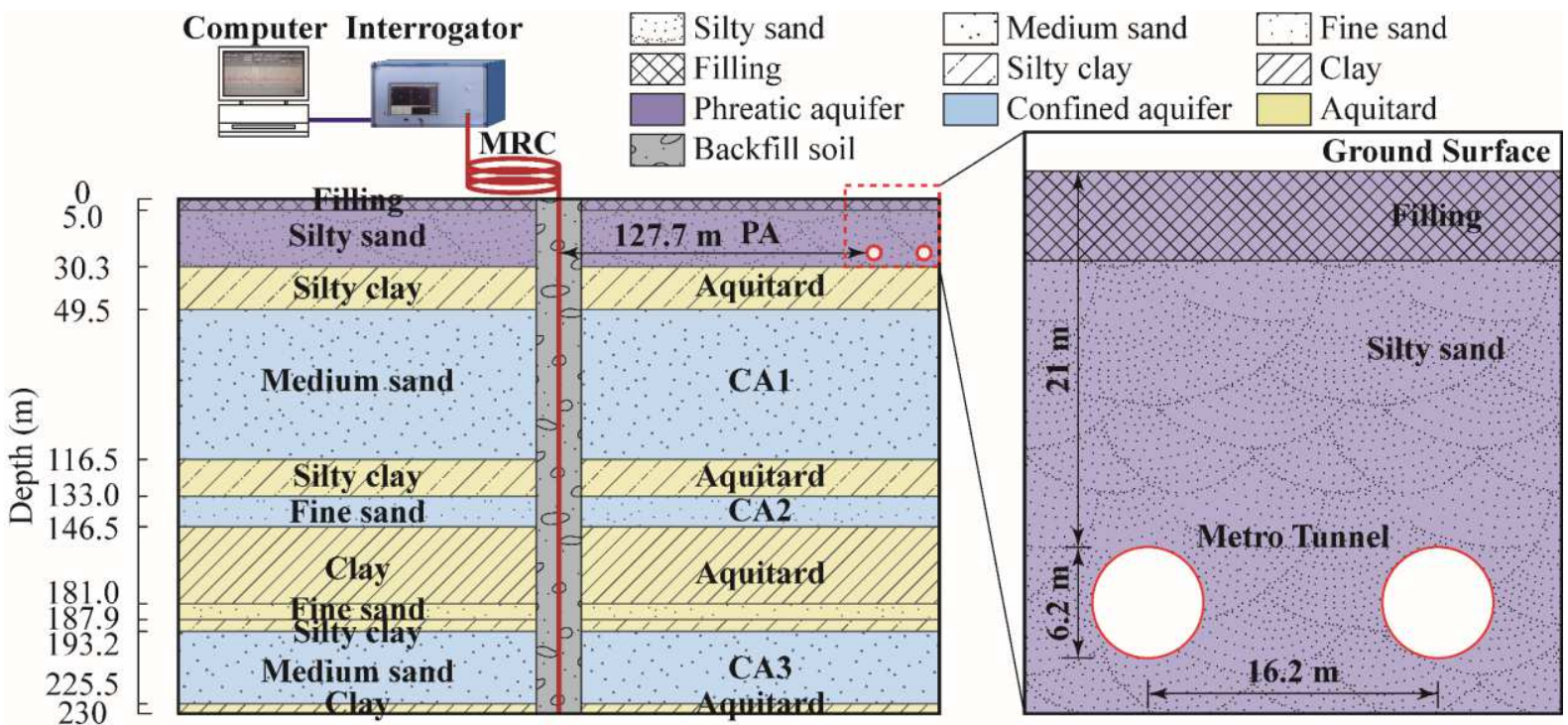

Fig. 4. The layout of subsurface deformation monitoring.

Table 2. Parameters of the BOTDR interrogator.

\begin{tabular}{ccccccc}
\hline Model & Resolution & Accuracy & Range & Distance & $\begin{array}{c}\text { Operating } \\
\text { wavelength }\end{array}$ & $\begin{array}{c}\text { Scanning } \\
\text { interval }\end{array}$ \\
\hline AV6419 & $0.05 \mathrm{~m}$ & $\pm 10 \mu \varepsilon$ & $\pm 15000 \mu \varepsilon$ & $0.5 \mathrm{~km}$ & $1550 \pm 5 \mathrm{~nm}$ & $5 \mathrm{MHz}$ \\
\hline
\end{tabular}


210 deformation field, were performed during the test. The monitoring of the water level of the

211 wells was implemented until no obvious variation can be observed. Three leveling calibrations

212 were conducted before pumping on June 11, June 28, and July 17, 2018, respectively.

213 Meanwhile, three rounds of DFOS measurements were acquired for calibration on Nov. 21,

214 Dec. 25, 2017, and Jan. 16, 2018, respectively. The monitoring schedule is depicted in Table 3.

215 Note that three rounds of DFOS measurements were collected per occurrence date.

Table 3. Occurrence dates of measurement.

\begin{tabular}{ccc}
\hline Period & Leveling & DFOS \\
\hline Pumping & Aug. 10; Aug. 13; Aug. 15 & Aug. 9 15 \\
& Aug. 18; Aug. 24; Aug. 30; Sep. 11; Sep. 28; & Aug. 16; Aug. 30; Sep. 5; Sep. 22; \\
Postpumping & Oct. 15; Oct. 26; Nov. 17; Nov. 29; & Oct. 10; Oct. 25; Nov. 13; \\
& Dec. 11; Dec. 23, 2018; Jan. 4; Jan. 16, 2019 & Dec. 27, 2018; Jan. 20, 2019 \\
\hline
\end{tabular}

217 4. Measuring results

$218 \quad 4.1$ Water level variation

219 From Aug. 9 to 15, 2018, the group pumping was conducted synchronously on the 15 wells

220 in Fig. 3. After stopping pumping for 30 days, the water level tended to be stable. The

221 measurements exhibit that before pumping, the initial water levels of the 15 wells were almost

222 the same, approximately $-16.1 \sim-17.5 \mathrm{~m}$. The water level sharply dropped during the pumping;

223 the decline rate of water level gradually slowed. The water level attained its minimum on the

224 sixth day of pumping. Fig. 5 (a) shows the distribution of the water level. As noted from the

225 figure, a total level drop of 11.39 16.50 m occurred on Aug. 15. Subsequently, a sharp rebound

226 of water level occurred on Aug. 16 right after the pumping; while the round rate obviously 
227 slowed down from Aug. 22. On August 30, 15 days after the pumping, the water level was

228 almost restored to its initial value, only with a level falling of $0.05 \sim 0.65 \mathrm{~m}$. The distribution of

229 the recovery values of water level is shown in Fig. 5(b). As seen from Fig. 5, the greatest decline

230 of the water level occurred near the center of the northern wells (W13), which is located near

231 both the river bank and the metro line. Note the rise and drop of water level exhibit similar

232 distribution patterns, suggesting the soil permeability of the west side is greater than that of the

233 east side, and the groundwater on the east side attains a stronger rechargeability.

234

235

236

237

238

239

240

241

242
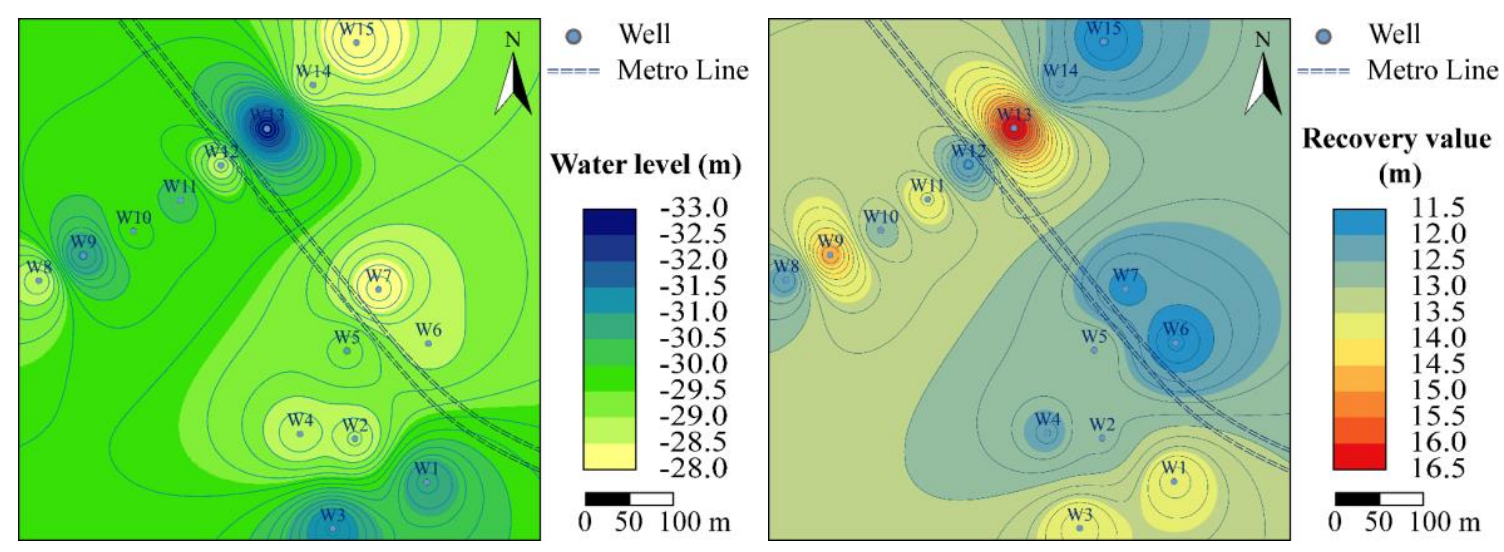

Fig. 5. Water level variation.

(a) Distribution of water level on Aug. 15;

(b) Distribution of water level recovery on Aug. 30.

\subsection{Surface settlement}

Fig. 6 shows the distribution patterns of the ground surface settlement, in which Fig. 6 (a) and (b) exhibit those during the pumping. As seen from Fig. 6 (a), at the initial stage of pumping, a large settlement occurred on the west side of the north well group; and also, a small range of settlement occurred in the south well group. The greatest settlement occurred at the measuring point S9, with a settlement value of $2.9 \mathrm{~mm}$. Tiny settlement occurred on the rest part. As seen 
244 from Fig. 6 (b), with the continuous pumping, a small amount of settlement appears on the wide

245 range of the site, and the settlement area of the west side of the north well group enlarged a

246 little. The maximum of settlement occurred on measuring point S22, with a settlement value of

$2473.1 \mathrm{~mm}$. In addition, the settlement values of the east side of the embankment and the south

248 well group are both small, suggesting a plenty supply of groundwater.

249 Fig. (7) shows the distribution pattern of settlement within the five months after the pumping.

250 As shown from Fig. 7(a), within two weeks after the end of pumping, the settlement range

251 further enlarged, and the maximum settlement, with a value of $3.3 \mathrm{~mm}$, occurred on measuring

252 point S23, the west side near the embankment, suggesting that the settlement behavior lagged

253 the deep pumping activity. As seen from Fig. 7 (b), the settlement area gradually merged to

254 exhibit a large range of the settlement area, which is similar to the distribution pattern of the

255 variation of water levels in the wells. A large settlement occurred on the west side of the north

256 well group and the distribution is continuous. The maximum of the settlement occurred at the

257 measuring point S14, with a settlement value of $3.8 \mathrm{~mm}$. As seen from Fig. 7 (c), the settlement

258 area did not vary significantly 3 months after the pumping. However, a notably concentrated

259 settlement occurred on measuring point S21, on the west side of the embankment, with a value

260 of $4.4 \mathrm{~mm}$, which is the greatest settlement value of the test, again manifesting that the ground

261 settlement lags the deep pumping. As seen from Fig. 7 (d), the settlement at the measuring point

262 S21 gradually dissipated and its range expanded. The settlement value decreased to $3.3 \mathrm{~mm}$.

263 Note that no obvious ground settlement occurred in this test, suggesting that the existence of 
265 indicate that the permeability of the strata on the west side is greater than that of the east side.
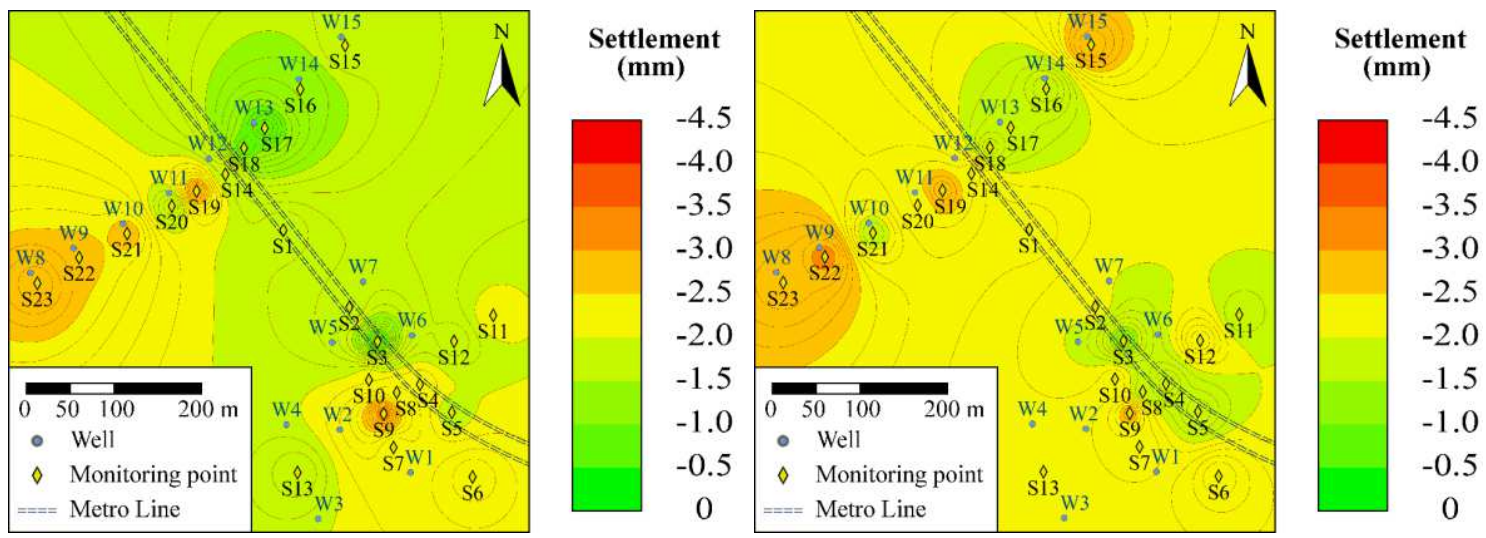

Fig. 6. The variation of surface settlement distribution during the pumping.

(a) Aug. 10, 2018; (b) Aug. 15, 2018.
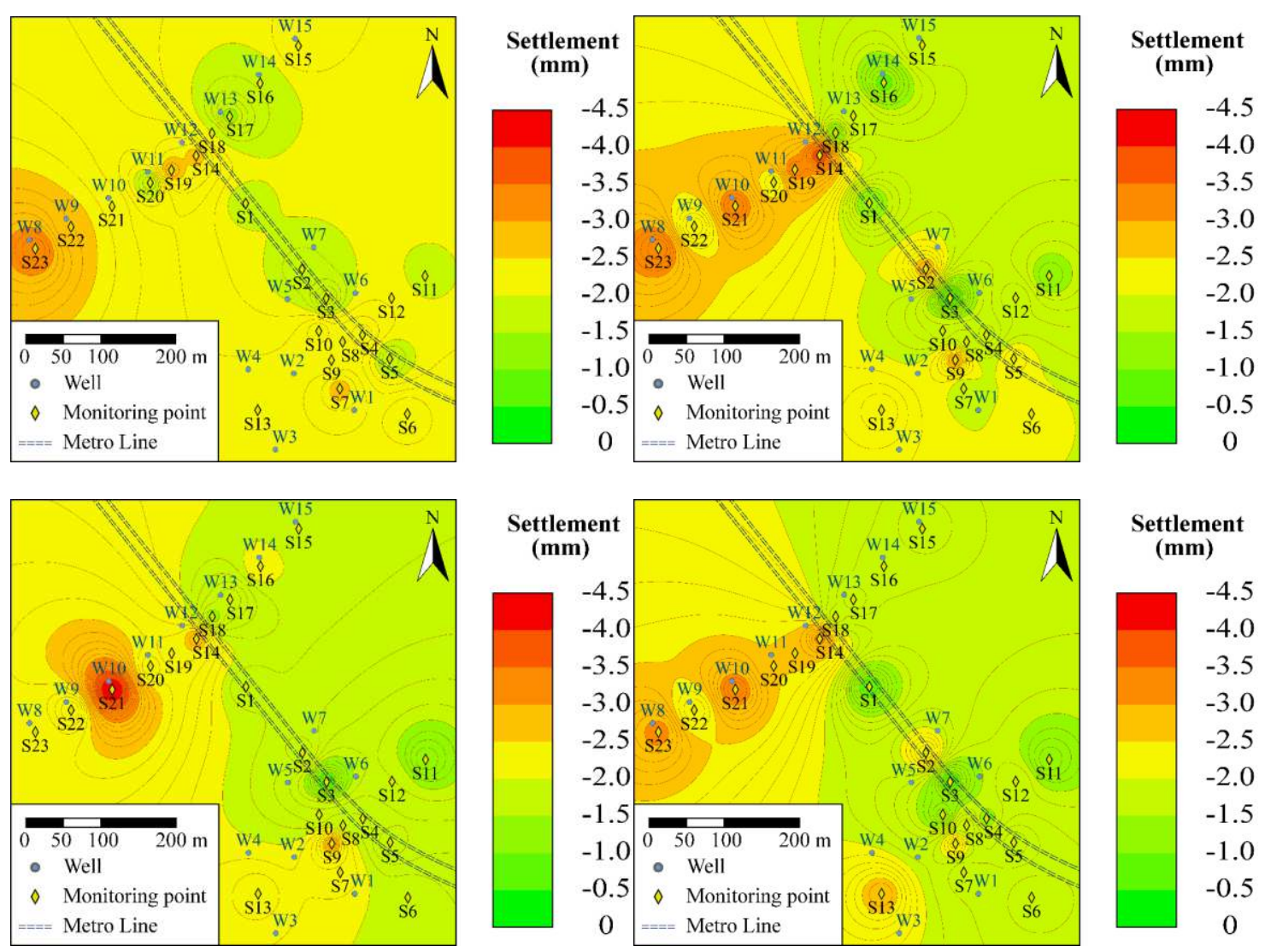

Fig. 7. The variation of surface settlement distribution after the pumping.

(a) Aug 24, 2018; (b) Sep. 11, 2018; (c) Nov. 17, 2018; (d) Jan. 16, 2019. 


\subsection{Characterization of the subsurface deformation field}

274 In order to further study the influence of the groundwater barrier on the deformation 275 connectivity of the strata, the subsurface deformation values acquired by DFOS were

276 substituted into the space-time matrix $\boldsymbol{B}$. Note the buried depth of the constant-temperature

277 layer of the test site is from 10 to $230 \mathrm{~m}$; thus, the measurements of the strain field ranging

278 from the ground surface to $10 \mathrm{~m}$ underground were excluded owing to the measuring 279 uncertainty induced by the temperature variation in the variable temperature layer. Thus, the

280 submatrices of the constant-temperature layer were extracted to plot the strain field contours

281 during and after the pumping, as shown in Fig. 8. As can be noted from the figure, the strain 282 concentrates within the acquire layers in Fig. 4. Specifically, restricted by the aquiclude of the 283 clayey layer ranging from the buried depth of 150 to $180 \mathrm{~m}$, the greater strain mainly occurs 284 within aquifer CA3 from the buried depth of 180 230 m.

285 As seen from Fig. 8(a), during the pumping, the strain values within the buried depth of 10 180 m were tiny. Note obvious compressive strain occurred within aquifer CA3, which corresponds to average daily subsidence of approximately $1.61 \sim 2.87 \mathrm{~mm}$ calculated by Eq. (7).

As seen from Fig. 8(b), after the pumping, the strata strain field, ranging from the buried depth of 10 180 m, varied slightly; while the significant variation of the strata strain field occurred within 180 230 m underground. Although the strata exhibited compressive strain at the immediate end of pumping, tensile strain started occurring in half a month, suggesting the existence of an obvious and rapid stratum rebound and the rebound evolved from top to bottom.

293 One month after the end of pumping, the rebound extended from the upper part to the entire 
294 aquifer CA3. Four months after the end of pumping, the rebound rate slowed down owing to

295 the gradual recharging of the groundwater. The stratum rebound of aquifer CA3 ranges from

296 1.89 2.15mm, calculated by Eq. (7).

297

298

299

300

301

302

303

304

305

306

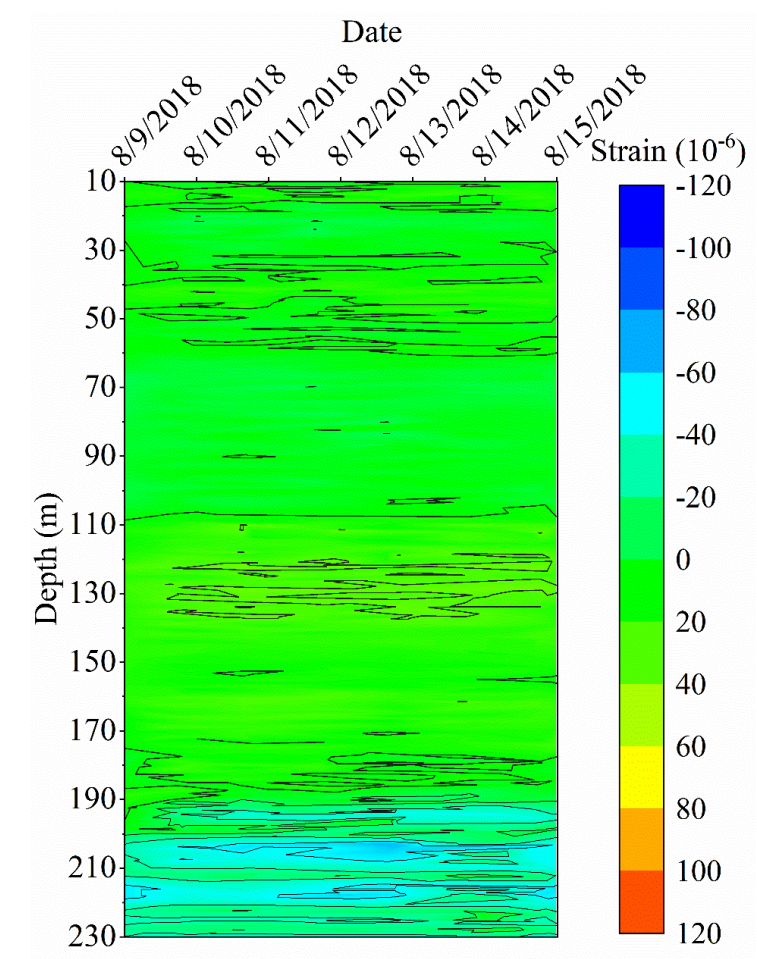

Fig. 8. Contour plot of the subsurface strain field.

(a) During the pumping; (b) After the pumping.

The stratigraphic strain field is converted to the accumulated subsurface deformation in accordance with Eq. (7). Fig (9) compares variation trends of both cumulative subsurface deformation of aquifer CA3 and the corresponding surface settlement over time. As seen from the figure, the surface subsided slightly during the pumping. After the pumping, the settlement rate slowed down, and the maximum of settlement is $3.2 \mathrm{~mm}$, occurring on the 44th day, and then rebounded with small fluctuation. Meanwhile, a sharp compressive deformation of aquifer CA3 occurred during the pumping, and the deformation varied linearly with time. The 
307 deformation value reached the maximum of $18.24 \mathrm{~mm}$ on the first day after the end of the

308 pumping, and then a rebound occurred, whose rate slowed down with time. The deformation

309 of CA3 returned to the initial state five months after the end of pumping. Compared with the

310 subsurface deformation of CA3, the surface settlement is smaller and lagged about 1 to 2

311 months, suggesting the subsidence induced by the deep pumping is gradually transmitted to the

312 surface.

313

314

315

316

317

318

319

320

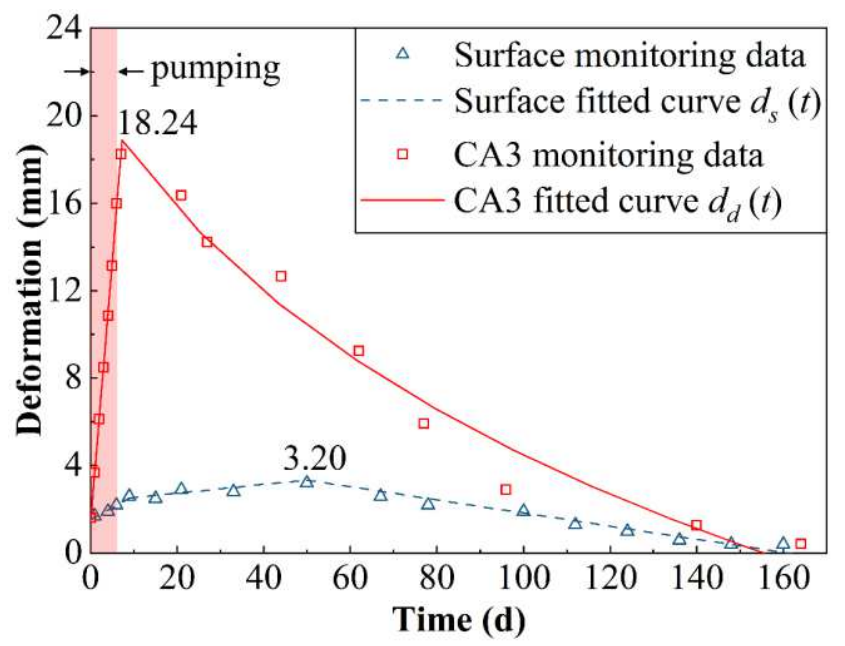

Fig. 9. Ground deformation trends and fitted curves of borehole D1.

\section{Discussion}

\subsection{Analysis of cumulative ground settlement}

As seen from Fig. 9, during the pumping state, aquifer CA3 and surface settlement increased linearly over time; during the postpumping stage, the surface settlement continued to increase linearly, but the rate decreased, while aquifer CA3 exhibited a nonlinear rebound trend. Note linear functions are used to fit aquifer CA3 and surface settlement trend during the pumping.

321 The logarithmic function is used to fit the rebound trend of CA3 during the postpumping, and 
322 a piecewise linear function is used to fit the surface subsidence and the rebound trend of the

323 postpumping stage, respectively. Eqs. (8) and (9) are the fitting functions of the deformation

324 trends of CA3 and ground surface, respectively.

$$
d_{d}(t)=\left\{\begin{array}{lc}
1.37+2.40 t & t \leq 7 \\
72.39-13.69 \ln (t+42.57) & t>7
\end{array}\right.
$$

326 where $d_{d}(t)$ (in $\mathrm{mm}$ ) is the cumulative deformation of aquifer CA3, and $\mathrm{t}$ (in days) is the duration.

327 Eq. (8) suggests that continuous pumping within the aquifer would induce sharp subsurface

328 deformation. The underground rebound follows a logarithmic trend and the rebound rate

329 slowed down with time.

$$
d_{s}(t)=\left\{\begin{array}{lr}
1.53+0.11 t & t \leq 9 \\
2.34+0.02 t & 9<t \leq 50 \\
4.84-0.03 t & t>50
\end{array}\right.
$$

331 where $d_{s}(t)$ (in $\mathrm{mm}$ ) is the cumulative settlement of surface, and $\mathrm{t}$ (in days) is the duration.

Eq. (9) shows that the surface will undergo linear settlement over time during the pumping, and will continue to settle at a low rate after the pumping. This stage of settlement lasted as

334 long as 43 days; such comprises the major part of the total settlement. Subsequently, the surface

335 rebounded linearly with time, and the time recovering to the initial state was the same as that 336 of CA3, suggesting the surface settlement after the pumping is closely related to the subsurface 337 deformation.

338 Note that the surface settlement was divided into two phases, the former was closely 339 associated with the pumping and the latter was closely related to CA3 stratigraphic deformation.

340 The duration of the surface settlement was nearly 50 days, which is about $1 / 3$ of the time 341 required for the surface rebound, and the time required for both aquifer CA3 and surface to 
342 recover to their initial state was about 150 days. When the water source pumping continuously

343 for $t_{p}$ days $\left(t_{p}>6\right)$, the duration of the formation to recover to its initial state is $t_{t}$, then according

344 to Eq. (8) satisfies

$$
72.39-13.69 \ln \left[\left(t_{t}-t_{p}+6\right)+42.57\right]+2.4\left(t_{p}-6\right)=0 \quad\left(t_{p}>6\right)
$$

346 Eq. (10) is derived to obtain the total recover duration of the strata $t_{t}$ and the duration of ground

347 surface settlement $t_{s}$, namely,

$$
t_{t}=3 t_{s}=\exp \left(\frac{57.99+2.4 t_{p}}{13.69}\right)-48.57+t_{p} \quad\left(t_{p}>6\right)
$$

349 Substituting into Eq. (9), the maximum surface settlement is

$$
\begin{aligned}
& d_{s}\left(t_{p}\right)=2.34+0.02 \times t_{s} \\
& \quad=2.02+0.02 t_{p}+1.38 \exp \left(0.175 t_{p}\right) \quad\left(t_{p}>6\right)
\end{aligned}
$$

According to Eq. (12), the maximum surface settlement increases approximately the relevant specifications (Gao et al., 2010). Therefore, the limit duration of continuous dewatering should not exceed 15 days.

\subsection{Analysis of the curvature radius along the metro line} deformation of the ground along the line. From Fig. 6 and Fig. 7, the settlement differences in the site traversed by this metro were more significant than those in other areas. The settlement

360 data from the settlement monitoring points along the metro line (S14, S1, S2, S3, S4, S5, and 
362 with time by the linear interpolation method, as shown in Fig. 10. The settlement was much

363 less than the specification limit of $20 \mathrm{~mm}$ (Gao et al., 2010). Also, obvious settlement grooves

364 occurred in both well groups, respectively, in the middle of which the settlement amount attains

365 the minimum. Note excessive relative settlement reduced the subsidence curvature radius.

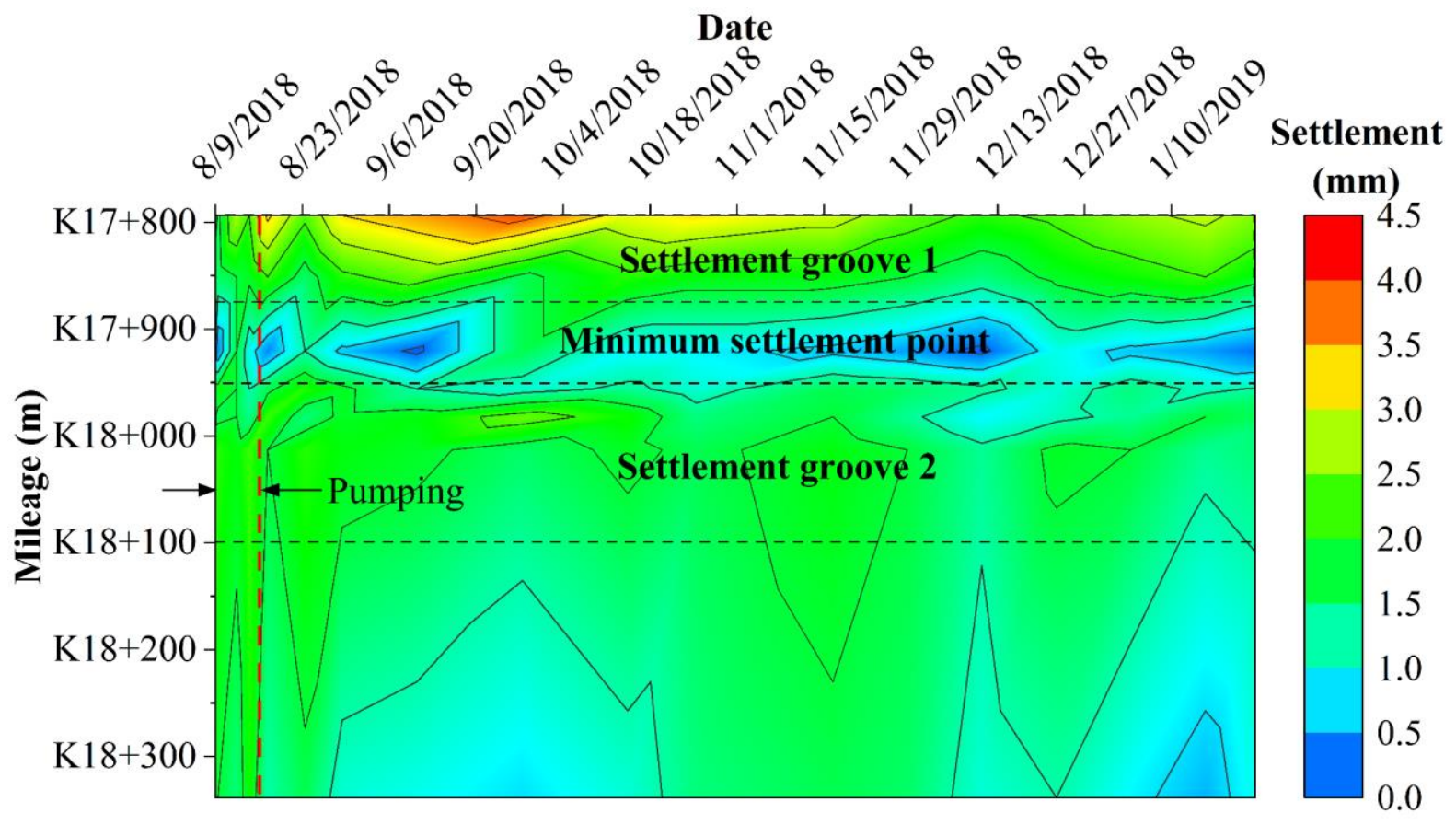

366

Fig. 10. Settlement distribution along the metro line.

The curvature radius, at each monitoring point along the metro line, induced by the longitudinal deformation of the tunnel was calculated by the three-point method (Cupec et al., the metro line occurred at settlement groove 2 on September 11 , with a radius of $3.89 \times 10^{6} \mathrm{~m}$.

374 Note that is much greater than the $1.5 \times 10^{4} \mathrm{~m}$ specified by the specification, indicating that the 
radius of those key points decreases exponentially with time during the pumping. Once the

377 pumping last more than 15 days, the curvature radius will be less than the standard value.

378 Within the first week after the end of the pumping, the curvature radius rose rapidly and then

379 fluctuated steadily, suggesting the variation of the longitudinal curvature radius of the tunnel is

380 closely related to the dewatering activities along the metro line.

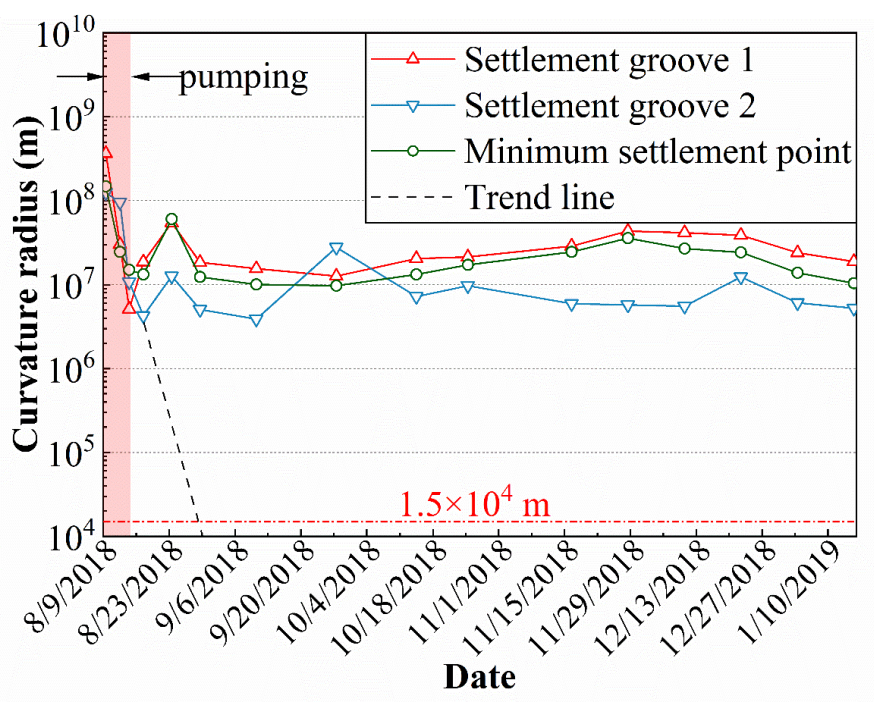

Fig. 11. The minimum curvature radius of typical sections along the metro line.

\section{CONCLUSIONS}

(1) The maximum surface settlement, produced by the 6-day pumping test, was about 4.4 $\mathrm{mm}$, which is less than the $20 \mathrm{~mm}$ limit required by the metro protection; the minimum curvature radius was $3.89 \times 10^{6} \mathrm{~m}$, which is much greater than the minimum limit of $1.5 \times 10^{4} \mathrm{~m}$ for the longitudinal deformation safety as specified in the specification.

(2) The fiber optic cable, vertically buried in the constant-temperature layer, can effectively measure the subsurface strain field and be used to deduce the deformation amount of each stratum based on the measurements. 
391 (3) After the end of pumping, a large settlement occurred on the west side of the test site,

392 which is consistent with the distribution pattern of groundwater level, suggesting the overall

393 distribution of settlement is combinedly affected by the formation permeability and 394 groundwater rechargeability.

395 (4) Influenced by the vertical distribution of aquitards, deep pumping causes the deformation

396 of the aquifers to be much greater than the surface settlement. Note the surface settlement lags

397 behind the settlement of the aquifer by 1 to 2 months; the surface rebound recovery also exhibits 398 a similar delay.

399 (5) During the pumping, the deformation of the aquifer and ground surface is linearly 400 compressed with time. After the pumping, the ground surface continues to settle linearly at a 401 slower rate for about 50 days, followed by a slow linear rebound; the aquifer is logarithmically 402 rebounded. Both rebounded to the initial state in about 150 days.

403 (6) During the pumping, the curvature radius of the settlement grooves along the metro line 404 decreased exponentially with time, and started to rise rapidly and maintained steady 405 fluctuations one week after the end of the pumping.

406 (7) Although the short-term continuous water supply from the groundwater source has 407 negligible adverse effects on the metro tunnel, the stratigraphic deformation fitting equations 408 indicates that the source should not be continuously pumped for more than 15 days. 
410 The authors would like to thank the anonymous reviewers for their helpful comments and

411 suggestions. This study was financially supported by the China Geological Survey (CGS)

412 Yangtze River Delta Area Nanjing-Shanghai-Wenzhou Urban Planning Area 1:50,000

413 Environmental Geological Survey Project (DD20160246) and the National Science Foundation

414 of China (grant Nos. 42077232).

\section{REFERENCES}

Abidin HZ, Djaja R, Darmawan D, Hadi S, Akbar A, Rajiyowiryono H, Sudibyo Y, Meilano I, Kasuma MA, Kahar J, Subarya C (2001) Land subsidence of Jakarta (Indonesia) and its geodetic monitoring system. Natural Hazards 23:365-387.

Baldi P, Casula G, Cenni N, Loddo F, Pesci A (2009) GPS-based monitoring of land subsidence in the Po Plain (Northern Italy). Earth and Planetary Science Letters 288:204-212.

Budhu M, Adiyaman IB (2010) Mechanics of land subsidence due to groundwater pumping. International Journal for Numerical and Analytical Methods in Geomechanics 34:1459-1478.

Calderhead AI, Therrien R, Rivera A, Martel R, Garfias J (2011) Simulating pumping-induced regional land subsidence with the use of InSAR and field data in the Toluca Valley, Mexico. Advances in Water Resources 34:83-97.

Chai J, Shen S, Zhu H, Zhang X (2004) Land subsidence due to groundwater drawdown in Shanghai. Geotechnique 54:143-147.

Choudhury P, Gahalaut K, Dumka R, Gahalaut VK, Singh AK, Kumar S (2018) GPS measurement of land subsidence in Gandhinagar, Gujarat (Western India), due to groundwater depletion. Environmental Earth Sciences 77:770. doi:10.1007/s12665-018-7966-5

Cui Z, Jia Y (2018) Physical model test of layered soil subsidence considering dual effects of building load and groundwater withdrawal. Arabian Journal for Science and Engineering 43:1721-1734.

Cupec R, Grbić R, Sabo K, Scitovski R (2009) Three points method for searching the best least absolute deviations plane. Applied Mathematics and Computation 215:983-994.

Edalat A, Khodaparast M, Rajabi AM (2020) Scenarios to control land subsidence using numerical modeling of groundwater exploitation: Aliabad plain (in Iran) as a case study. Environmental Earth Sciences 79:494. doi:10.1007/s12665-020-09246-2

Galloway DL, Burbey TJ (2011) Review: Regional land subsidence accompanying groundwater extraction. Hydrogeology Journal 19:1459-1486. 
Gao G, Gao M, Yang C, Yu Z (2010) Influence of deep excavation on deformation of operating metro tunnels and countermeasures. Chinese Journal of Geotechnical Engineering 32:453-459.

Gu K, Shi B, Liu C, Jiang H, Li T, Wu J (2018) Investigation of land subsidence with the combination of distributed fiber optic sensing techniques and microstructure analysis of soils. Engineering Geology 240:3447.

Herrera-García G, Ezquerro P, Tomás R, Béjar-Pizarro M, López-Vinielles J, Rossi M, Mateos RM, CarreónFreyre D, Lambert J, Teatini P, Cabral-Cano E, Erkens G, Galloway D, Hung W-C, Kakar N, Sneed M, Tosi L, Wang H, Ye S (2021) Mapping the global threat of land subsidence. Science 371:34-36. doi:10.1126/science.abb8549

Hu J, Chu H, Hou C, Lai T, Chen R, Nien P (2006) The contribution to tectonic subsidence by groundwater International 147:62-69.

Jiang X, Gao Y, Wu Y, Lei M (2016) Use of Brillouin optical time domain reflectometry to monitor soil-cave and sinkhole formation. Environmental Earth Sciences 75:225. doi:10.1007/s12665-015-5084-1

Kearns TJ, Wang G, Bao Y, Jiang J, Lee D (2015) Current land subsidence and groundwater level changes in the houston metropolitan area (2005-2012). Journal of Surveying Engineering 141.

Motagh M, Shamshiri R, Haghighi MH, Wetzel H-U, Akbari B, Nahavandchi H, Roessner S, Arabi S (2017) Quantifying groundwater exploitation induced subsidence in the Rafsanjan plain, southeastern Iran, using InSAR time-series and in situ measurements. Engineering Geology 218:134-151.

Mousavi SM, Shamsai A, Naggar MHE, Khamehchian M (2001) A GPS-based monitoring program of land subsidence due to groundwater withdrawal in Iran. Canadian Journal of Civil Engineering 28:452-464.

Othman A, Abotalib AZ (2019) Land subsidence triggered by groundwater withdrawal under hyper-arid conditions: case study from Central Saudi Arabia. Environmental Earth Sciences 78:243. doi:10.1007/s12665-019-8254-8

Pacheco-Martínez J, Hernandez-Marín M, Burbey TJ, González-Cervantes N, Ortíz-Lozano JÁ, Zermeño-DeLeon ME, Solís-Pinto A (2013) Land subsidence and ground failure associated to groundwater exploitation in the Aguascalientes Valley, México. Engineering Geology 163:172-186.

Peng J, Huang Q, Hu Z, Wang M, Li T, Men Y, Fan W (2017) A proposed solution to the ground fissure encountered in urban metro construction in Xi' an, China. Tunnelling and Underground Space Technology 61:12-25.

Poland M, Bürgmann R, Dzurisin D, Lisowski M, Masterlark T, Owen S, Fink J (2006) Constraints on the mechanism of long-term, steady subsidence at Medicine Lake volcano, northern California, from GPS, leveling, and InSAR. Journal of Volcanology and Geothermal Research 150:55-78.

Saleh M, Becker M (2018) New estimation of Nile Delta subsidence rates from InSAR and GPS analysis. Environmental Earth Sciences 78:6. doi:10.1007/s12665-018-8001-6

Shen S, Wu H, Cui Y, Yin Z (2014) Long-term subsidence behaviour of metro tunnels in the soft deposits of Shanghai. Tunnelling and Underground Space Technology 40:309-323.

Shen S, Xu Y (2011) Numerical evaluation of land subsidence induced by groundwater pumping in Shanghai. Canadian Geotechnical Journal 48:1378-1392.

Sun Y, Zhang D, Shi B, Tong H, Wei G, Wang X (2014) Distributed acquisition, characterization and process analysis of multi-field information in slopes. Engineering Geology 182:49-62. 
Wang Y, Zhang M, Hu F, Dong Y, Yu K (2018) A coupled one-dimensional numerical simulation of the land subsidence process in a multilayer aquifer system due to hydraulic head variation in the pumped layer. Geofluids 2018.

Wang Z, Shen S, Cheng W, Xu Y (2016) Ground fissures in Xi'an and measures to prevent damage to the Metro tunnel system due to geohazards. Environmental Earth Sciences 75:511.

Wu J, Jiang H, Su J, Shi B, Jiang Y, Gu K (2015) Application of distributed fiber optic sensing technique in land subsidence monitoring. Journal of Civil Structural Health Monitoring 5:587-597.

488 Xu B, Yan C, Sun Q, Liu Y, Hou J, Liu S, Che C (2016a) Field pumping experiments and numerical simulations of shield tunnel dewatering under the Yangtze River. Environmental Earth Sciences 75:715. doi:10.1007/s12665-016-5493-9

Xu Y, Ma L, Du Y, Shen S (2012) Analysis of urbanisation-induced land subsidence in Shanghai. Natural Hazards 63:1255-1267.

Xu Y, Shen S, Ren D, Wu H (2016b) Analysis of factors in land subsidence in shanghai: A view based on a strategic environmental assessment. Sustainability 8:573.

Xue Y, Zhang Y, Ye S, Wu J, Li Q (2005) Land subsidence in China. Environmental Geology 48:713-720.

Zhang C, Shi B, Gu K, Liu S, Wu J, Zhang S, Zhang L, Jiang H, Wei G (2018) Vertically distributed sensing of deformation using fiber optic sensing. Geophysical Research Letters 45:11732-11741.

Zhang C, Shi B, Zhu H, Wang B, Wei G (2020) Toward Distributed Fiber - Optic Sensing of Subsurface Deformation: A Theoretical Quantification of Ground - Borehole - Cable Interaction. Journal of Geophysical Research: Solid Earth 125.

Zhang C, Zhu H, Shi B, She J (2014) Interfacial characterization of soil-embedded optical fiber for ground deformation measurement. Smart Materials and Structures 23:095022.

Zhang Y, Wu J, Xue Y, Wang Z (2017) Fully coupled three-dimensional nonlinear numerical simulation of pumping-induced land movement. Environmental Earth Sciences 76:552.

Zheng G, Zeng C, Xue X (2014) Settlement mechanism of soils induced by local pressure-relief of confined aquifer and parameter analysis. Chinese Journal of Geotechnical Engineering 36:802-817. 


\section{Table headings}

Table 1. Physical and mechanical parameters of soils.

Table 2. Parameters of the BOTDR interrogator.

Table 3. Occurrence dates of measurement.

\section{Figure captions}

Fig. 1. The structure of a metal-reinforced single-core cable (MRC).

Fig. 2. Location of the test site.

Fig. 3. Test layout.

Fig. 4. The layout of subsurface deformation monitoring.

Fig. 5. Water level variation.

(a) Distribution of water level on Aug. 15

(b) Distribution of water level recovery on Aug. 30

Fig. 6. The variation of surface settlement distribution during the pumping.

(a) Aug. 10, 2018

(b) Aug. 15, 2018

Fig. 7. The variation of surface settlement distribution after the pumping.
(a) Aug 24, 2018
(b) Sep. 11, 2018
(c) Nov. 17, 2018
(d) Jan. 16, 2019

Fig. 8. Contour plot of the subsurface strain field.

(a) During the pumping

(b) After the pumping

Fig. 9. Ground deformation trends and fitted curves of borehole D1.

Fig. 10. Settlement distribution along the metro line.

Fig. 11. The minimum curvature radius of typical sections along the metro line. 
Figures

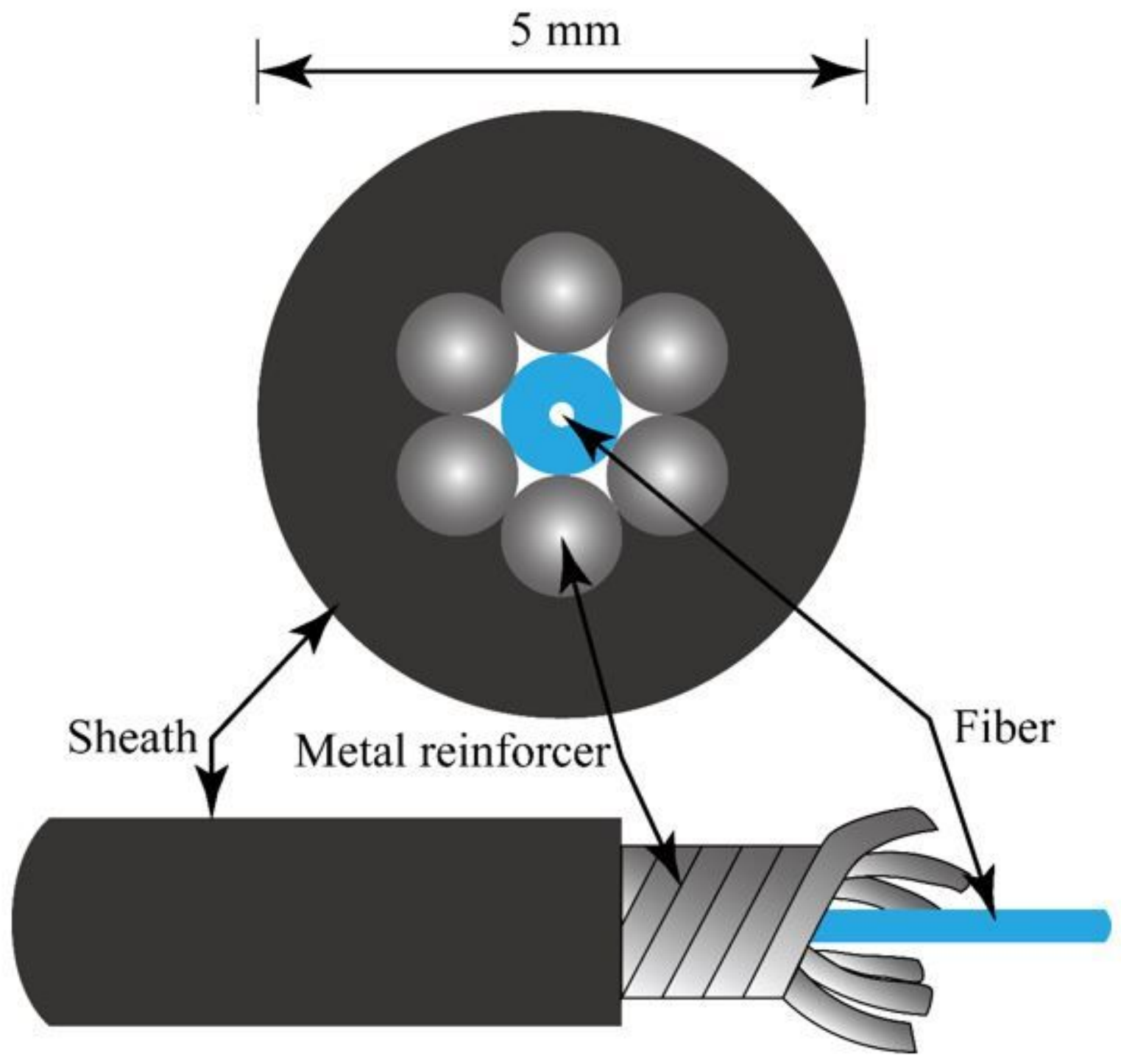

Figure 1

The structure of a metal-reinforced single-core cable (MRC). 


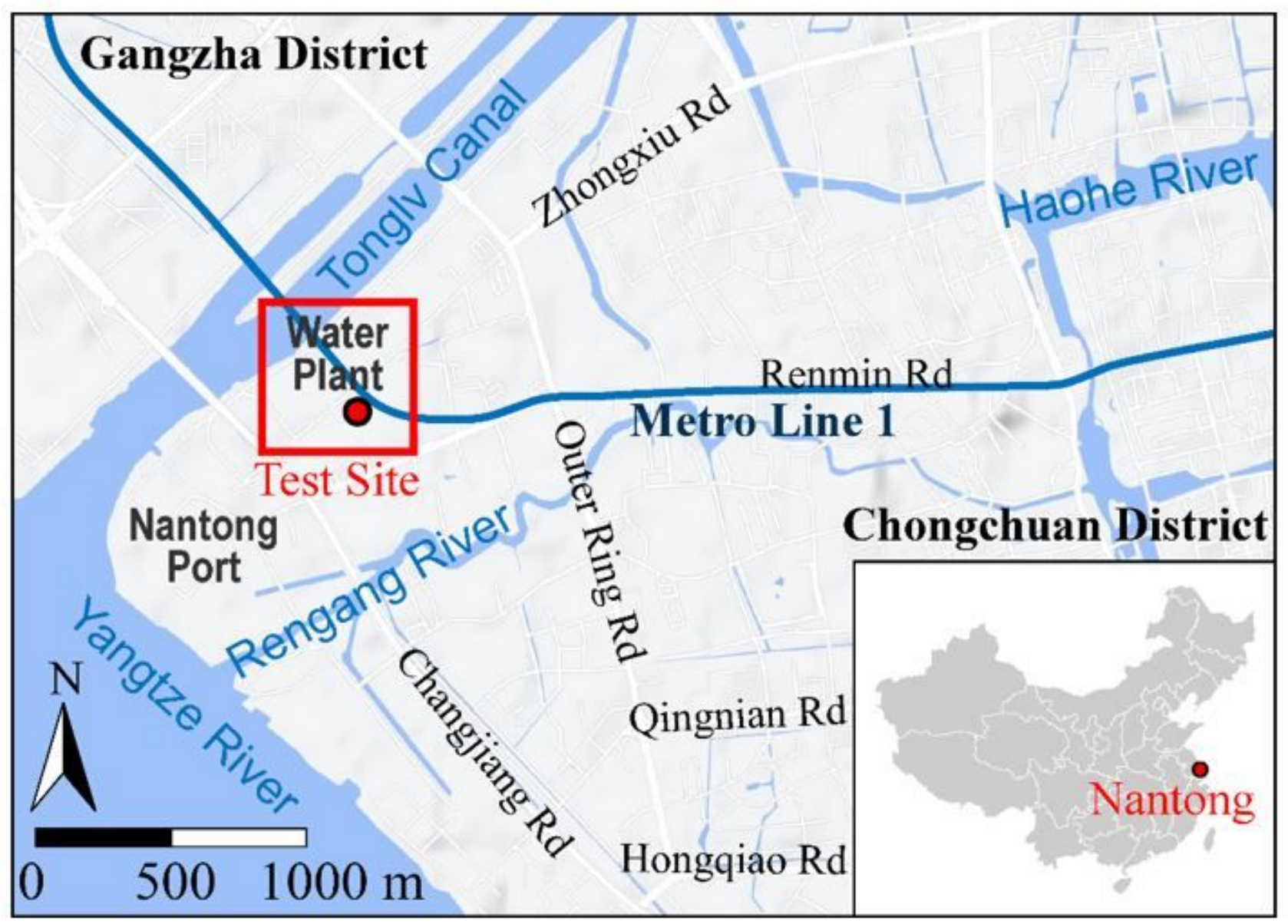

Figure 2

Location of the test site. Note: The designations employed and the presentation of the material on this map do not imply the expression of any opinion whatsoever on the part of Research Square concerning the legal status of any country, territory, city or area or of its authorities, or concerning the delimitation of its frontiers or boundaries. This map has been provided by the authors. 


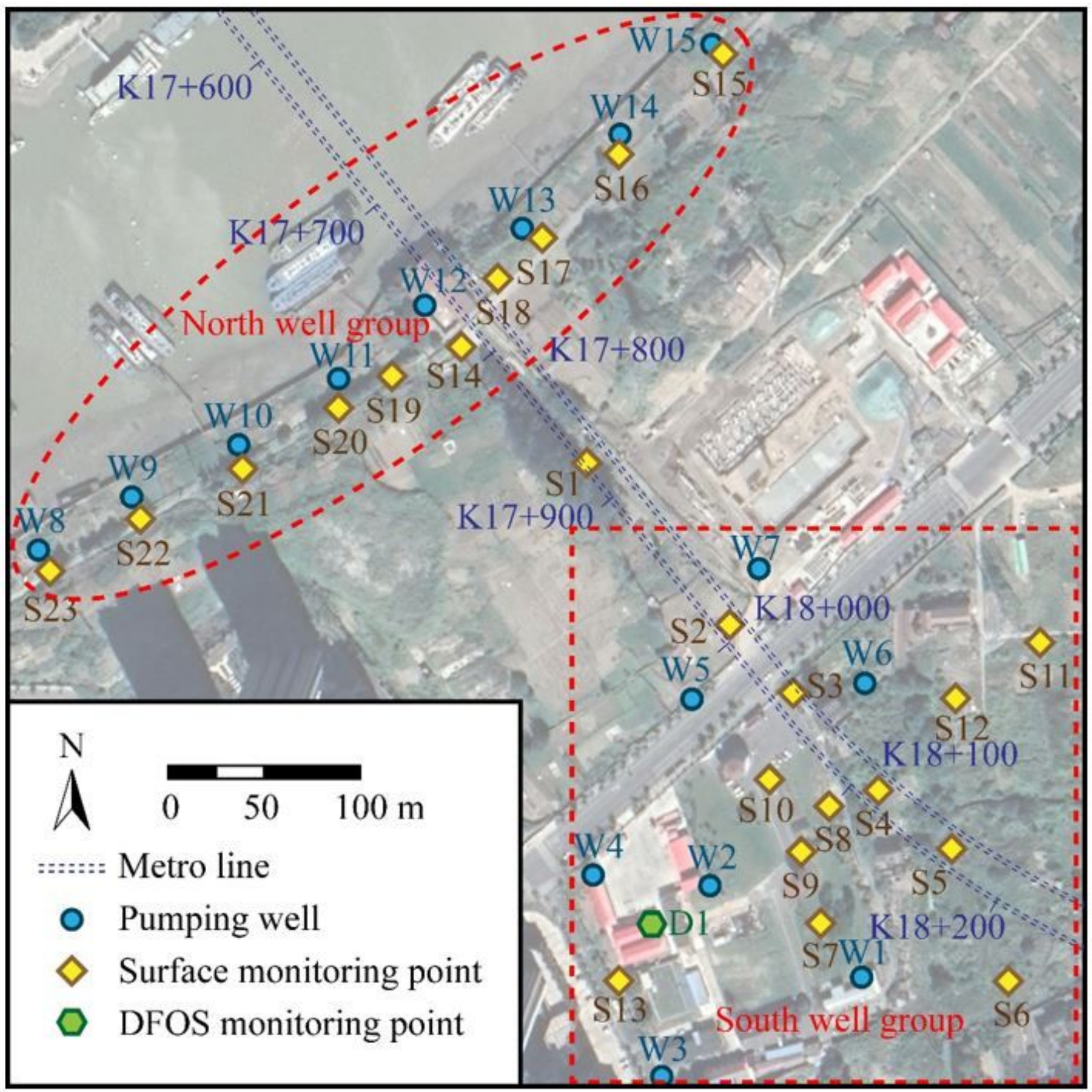

Figure 3

Test layout. Note: The designations employed and the presentation of the material on this map do not imply the expression of any opinion whatsoever on the part of Research Square concerning the legal status of any country, territory, city or area or of its authorities, or concerning the delimitation of its frontiers or boundaries. This map has been provided by the authors. 


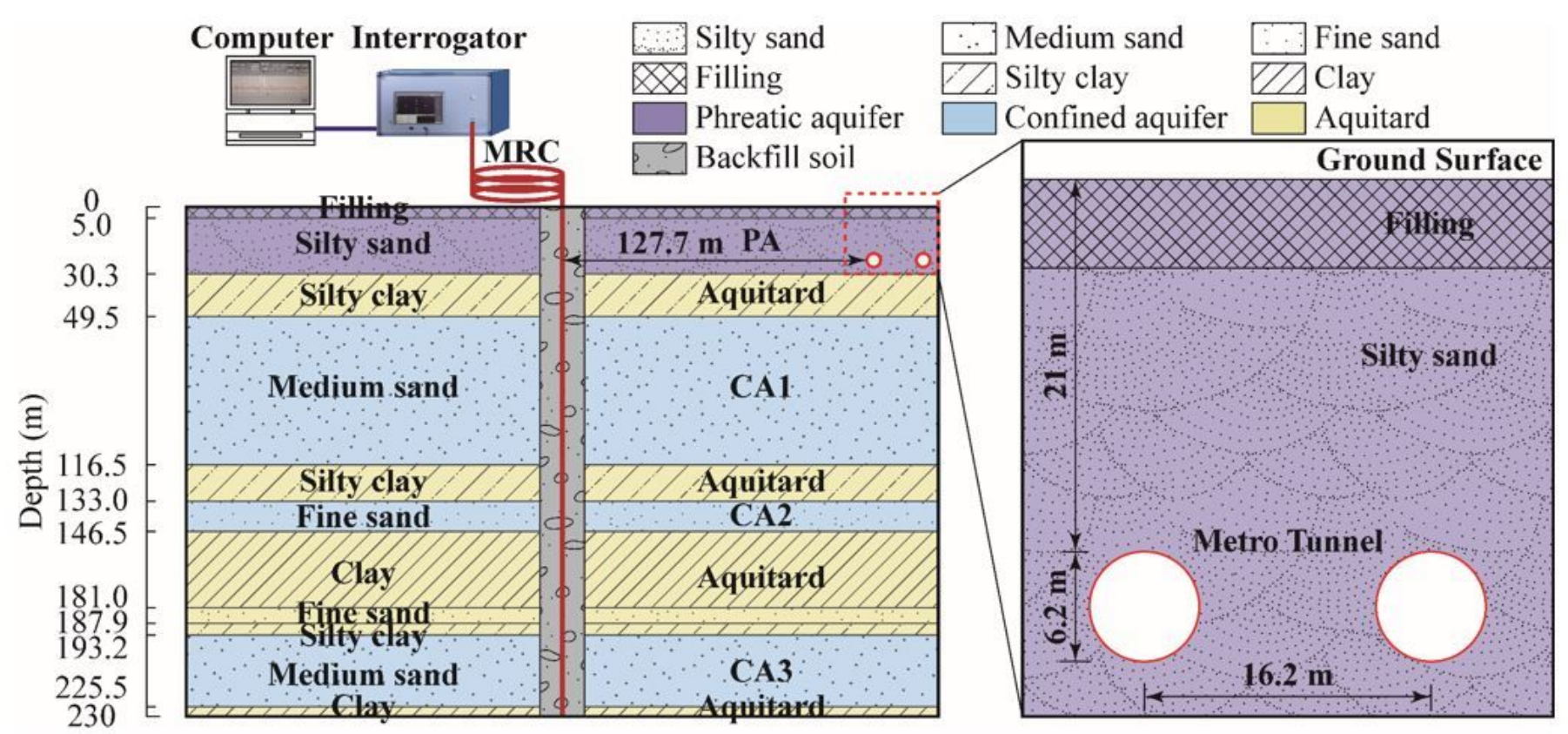

Figure 4

The layout of subsurface deformation monitoring.
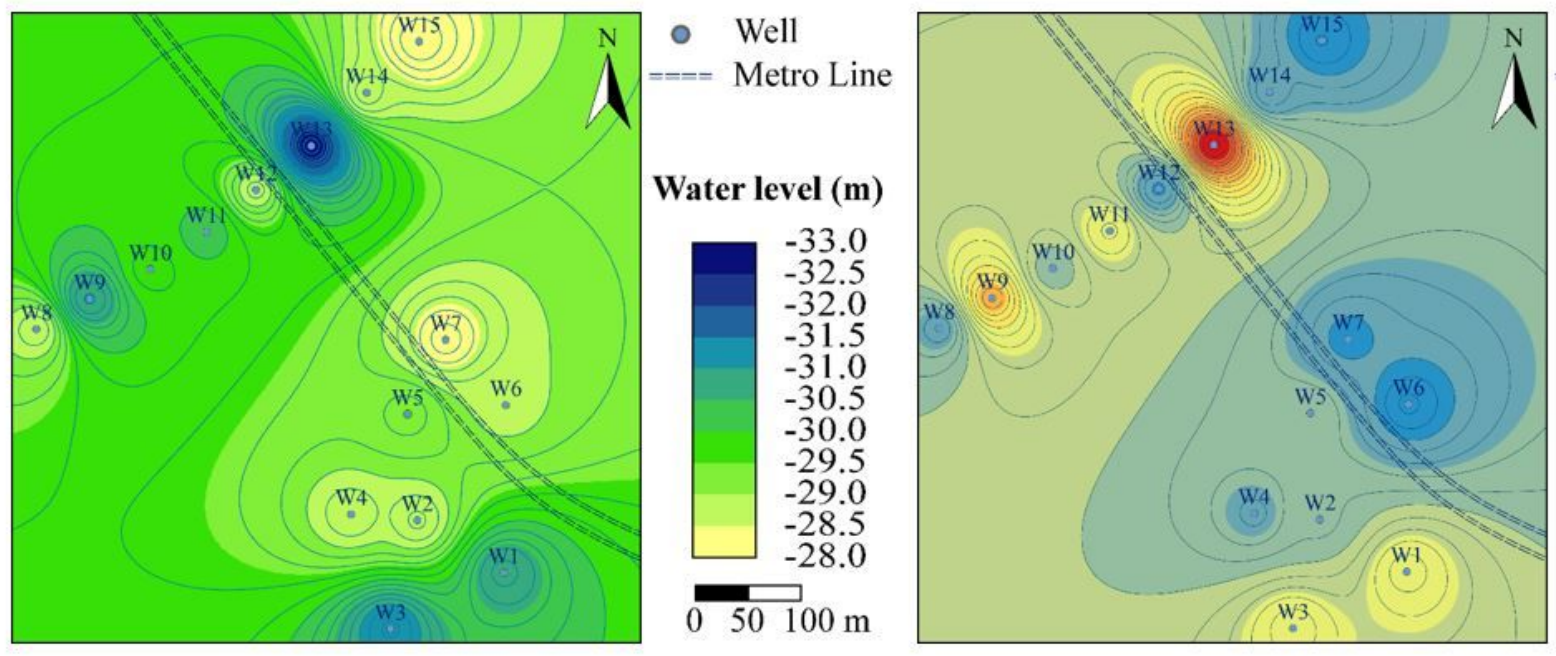

Well
$====$ Metro Line
Recovery value

(m)

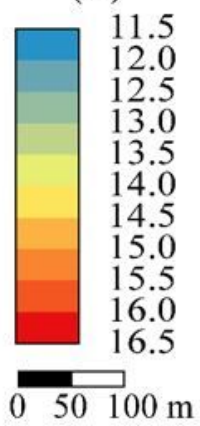

Figure 5

Water level variation. (a) Distribution of water level on Aug. 15; (b) Distribution of water level recovery on Aug. 30. Note: The designations employed and the presentation of the material on this map do not imply the expression of any opinion whatsoever on the part of Research Square concerning the legal status of any country, territory, city or area or of its authorities, or concerning the delimitation of its frontiers or boundaries. This map has been provided by the authors. 

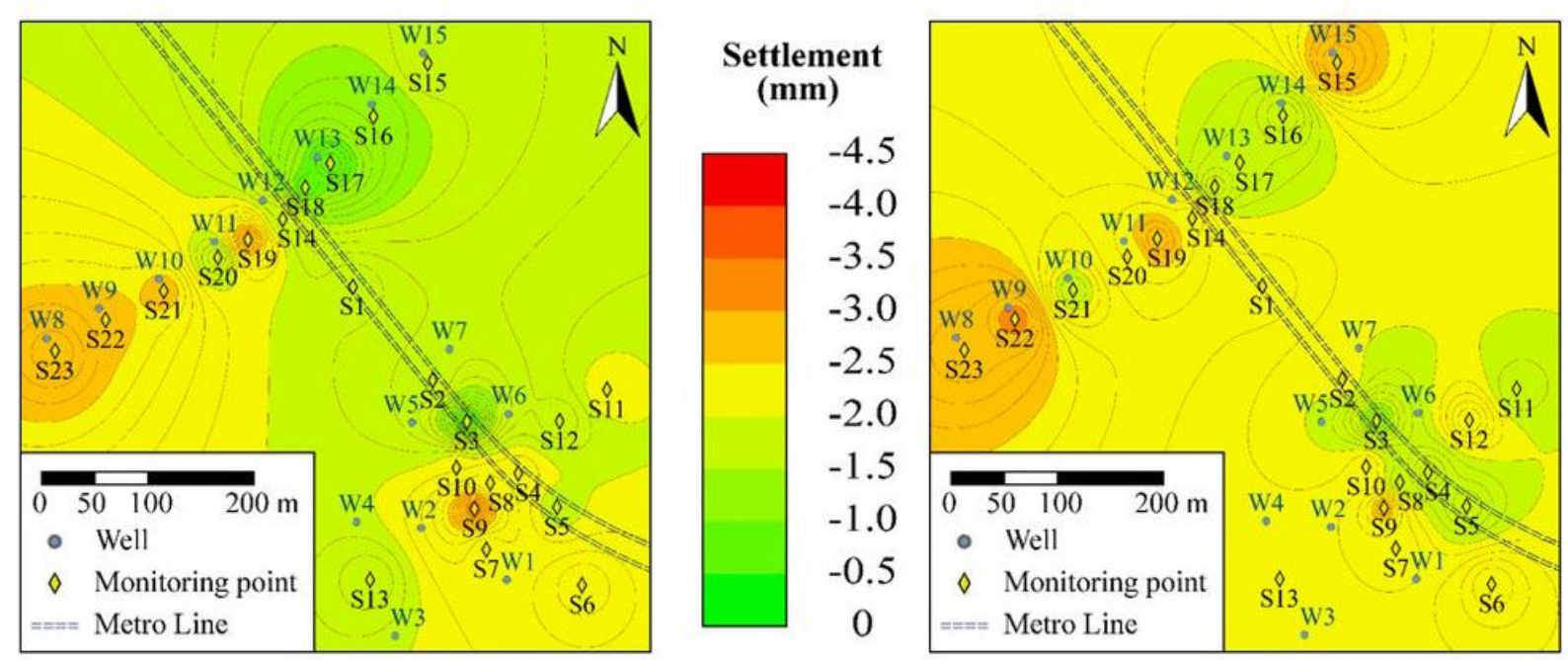
Settlement (mm)

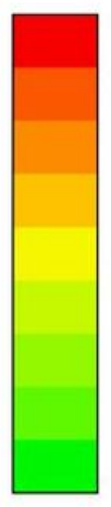

$-4.5$

$-4.0$

$-3.5$

$-3.0$

$-2.5$

$-2.0$

$-1.5$

$-1.0$

$-0.5$

0

\section{Figure 6}

The variation of surface settlement distribution during the pumping. (a) Aug. 10, 2018; (b) Aug. 15, 2018. Note: The designations employed and the presentation of the material on this map do not imply the expression of any opinion whatsoever on the part of Research Square concerning the legal status of any country, territory, city or area or of its authorities, or concerning the delimitation of its frontiers or boundaries. This map has been provided by the authors. 

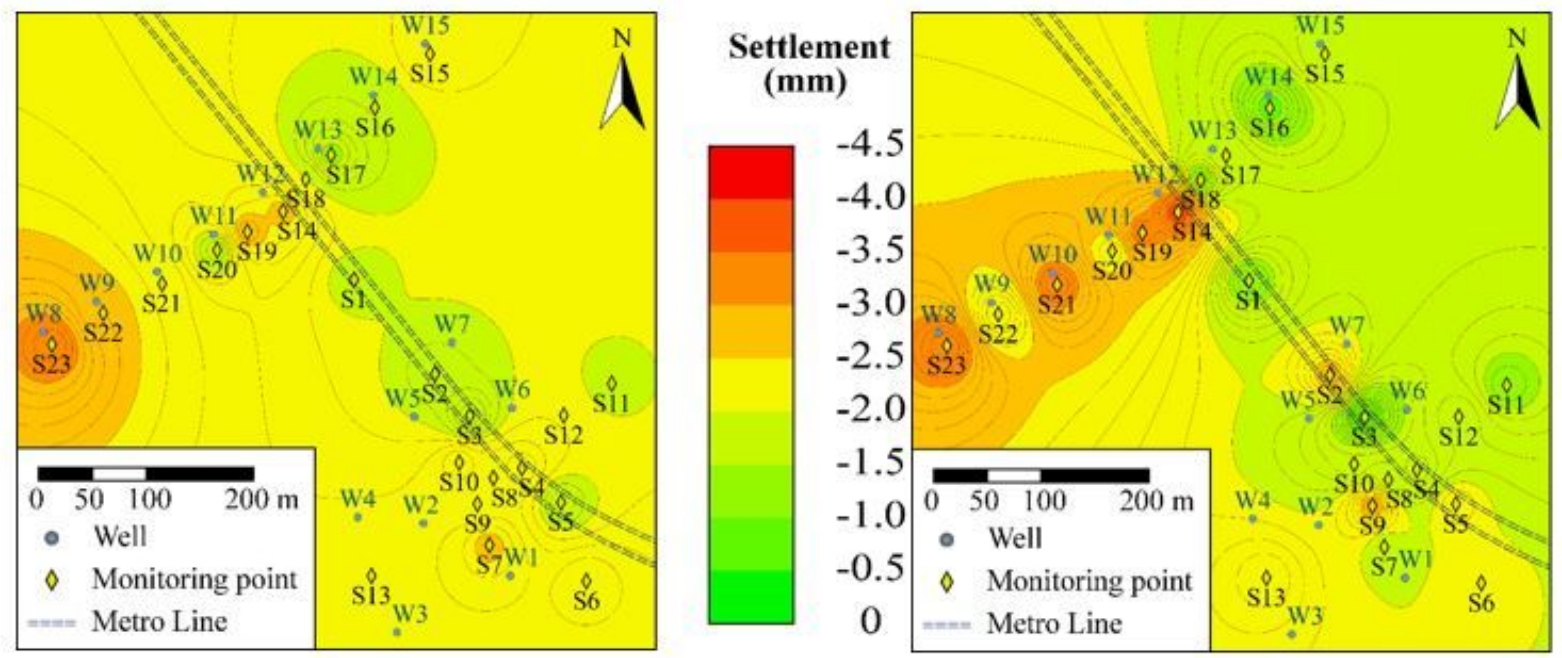

Settlement

(mm)

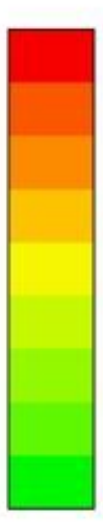

$-4.5$

$-4.0$

$-3.5$

$-3.0$

$-2.5$

$-2.0$

$-1.5$

$-1.0$

$-0.5$

0
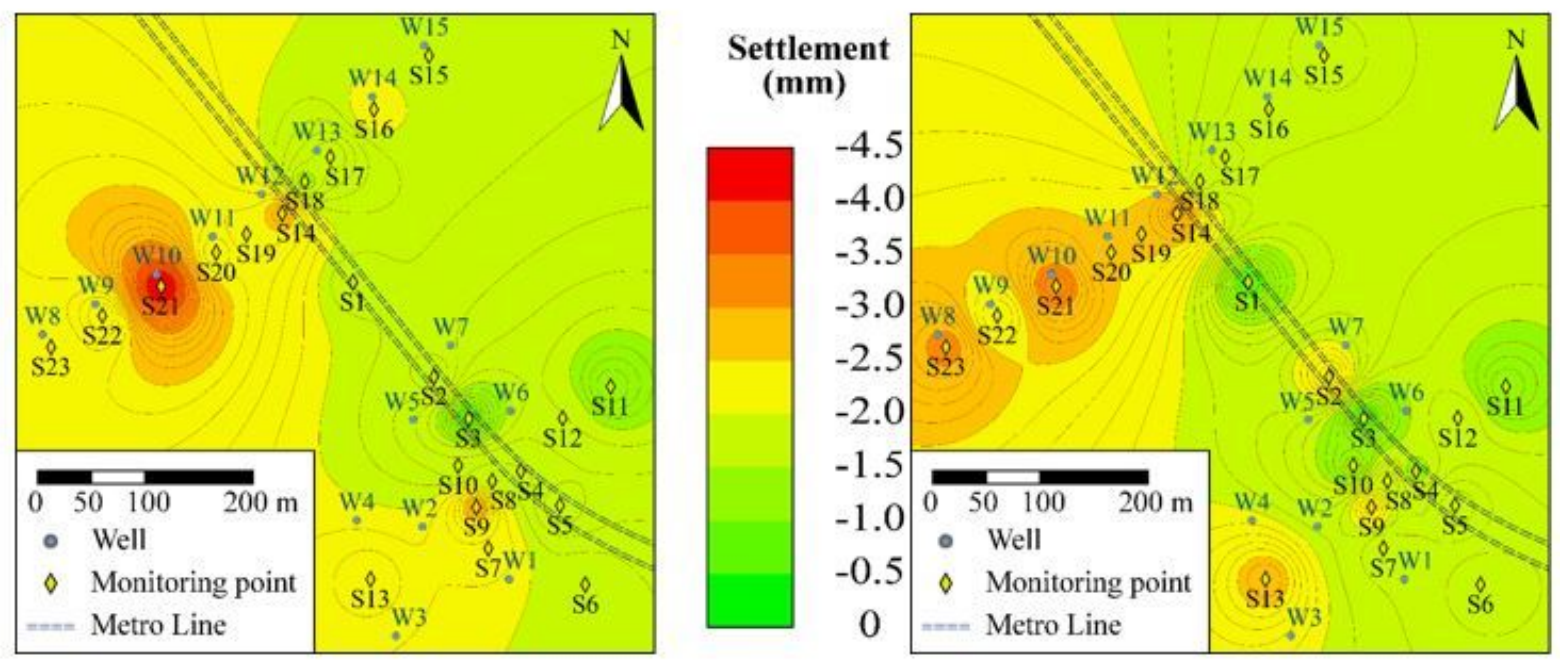

\section{Settlement} (mm)

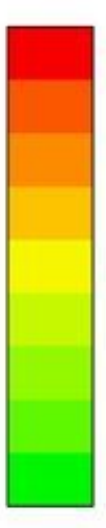

$-4.5$

$-4.0$

$-3.5$

$-3.0$

$-2.5$

$-2.0$

$-1.5$

$-1.0$

$-0.5$

0

\section{Figure 7}

The variation of surface settlement distribution after the pumping. (a) Aug 24, 2018; (b) Sep. 11, 2018; (c) Nov. 17, 2018; (d) Jan. 16, 2019. Note: The designations employed and the presentation of the material on this map do not imply the expression of any opinion whatsoever on the part of Research Square concerning the legal status of any country, territory, city or area or of its authorities, or concerning the delimitation of its frontiers or boundaries. This map has been provided by the authors. 

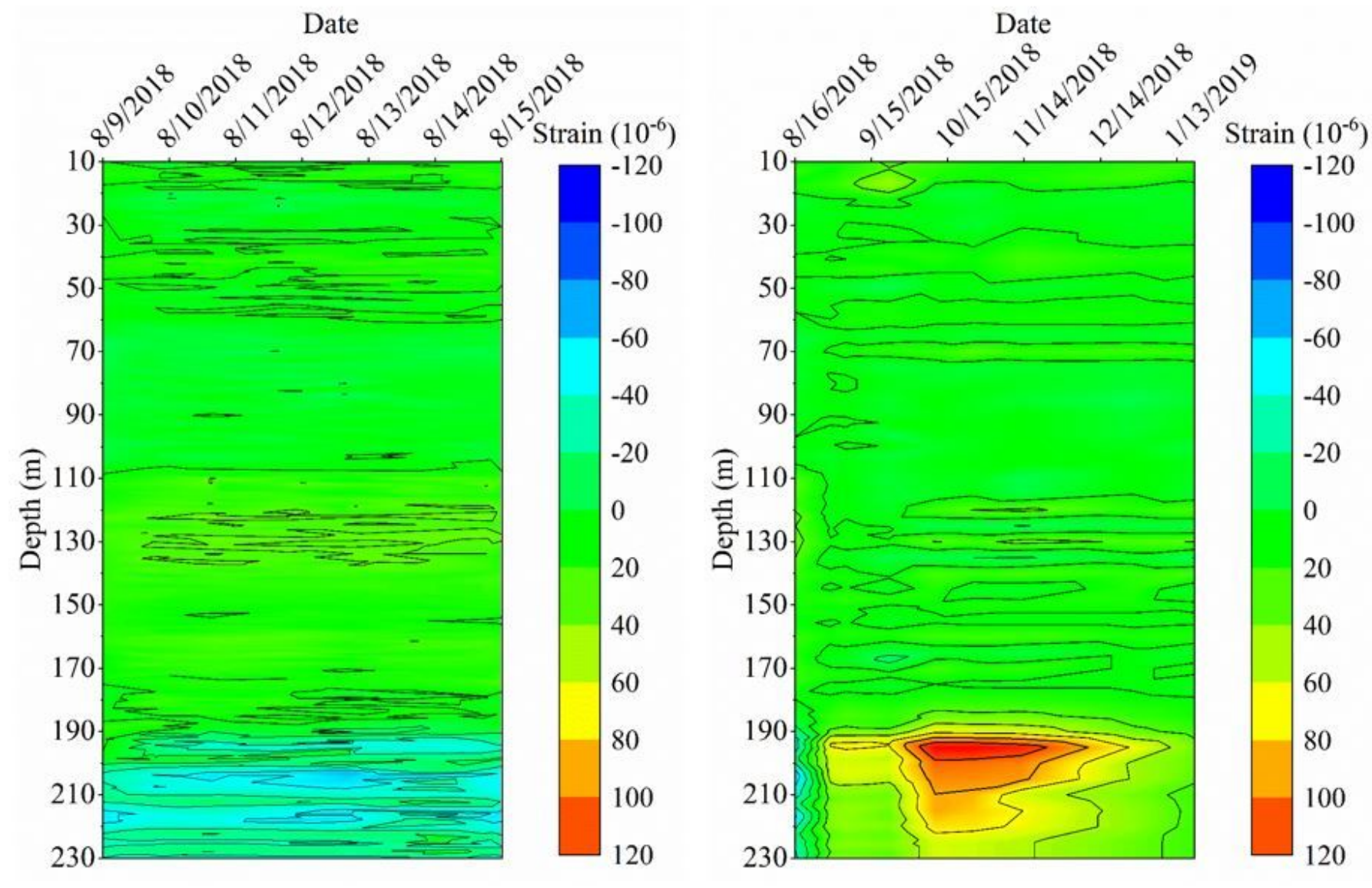

Figure 8

Contour plot of the subsurface strain field. (a) During the pumping; (b) After the pumping. 


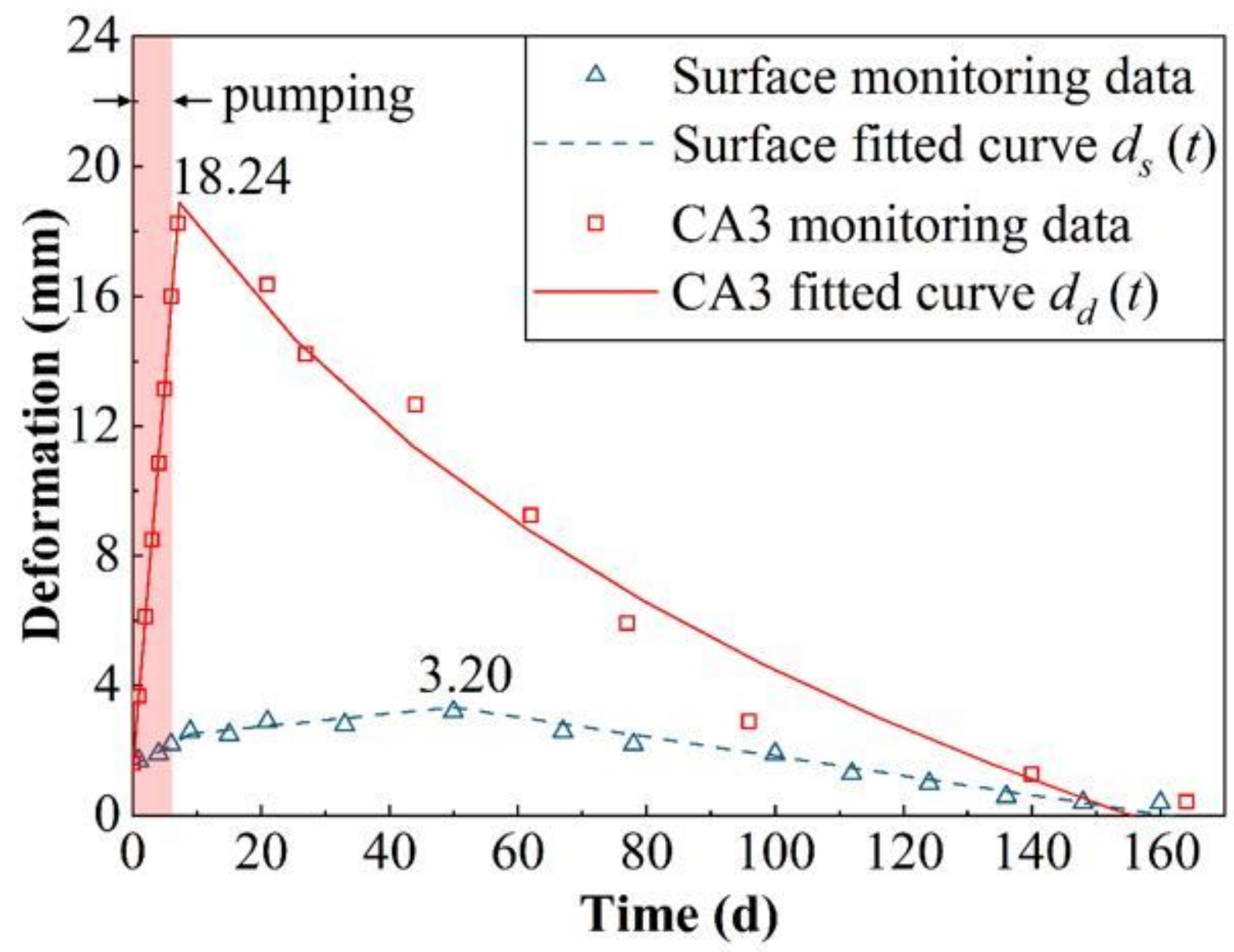

Figure 9

Ground deformation trends and fitted curves of borehole D1. 


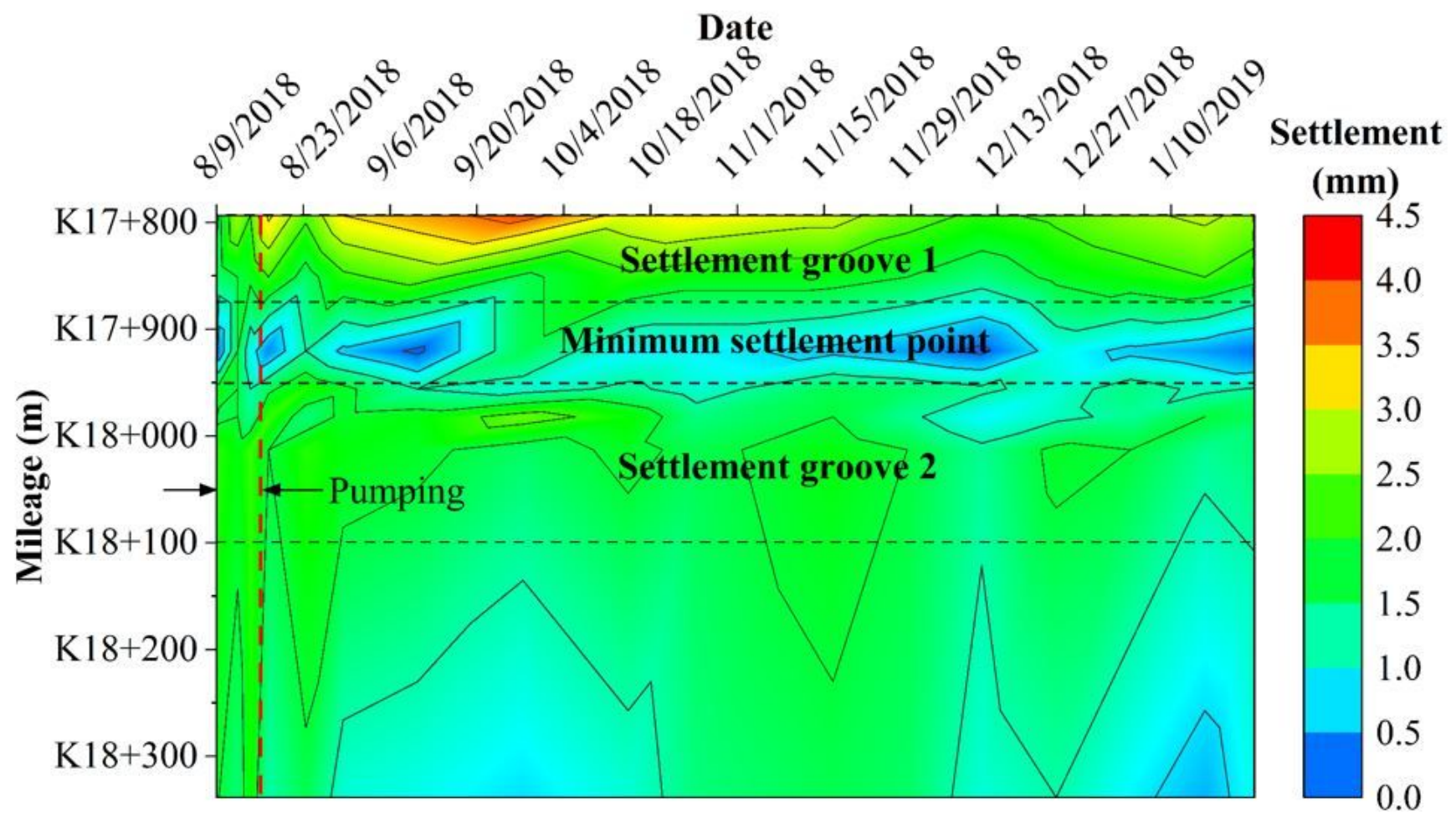

Figure 10

Settlement distribution along the metro line. 


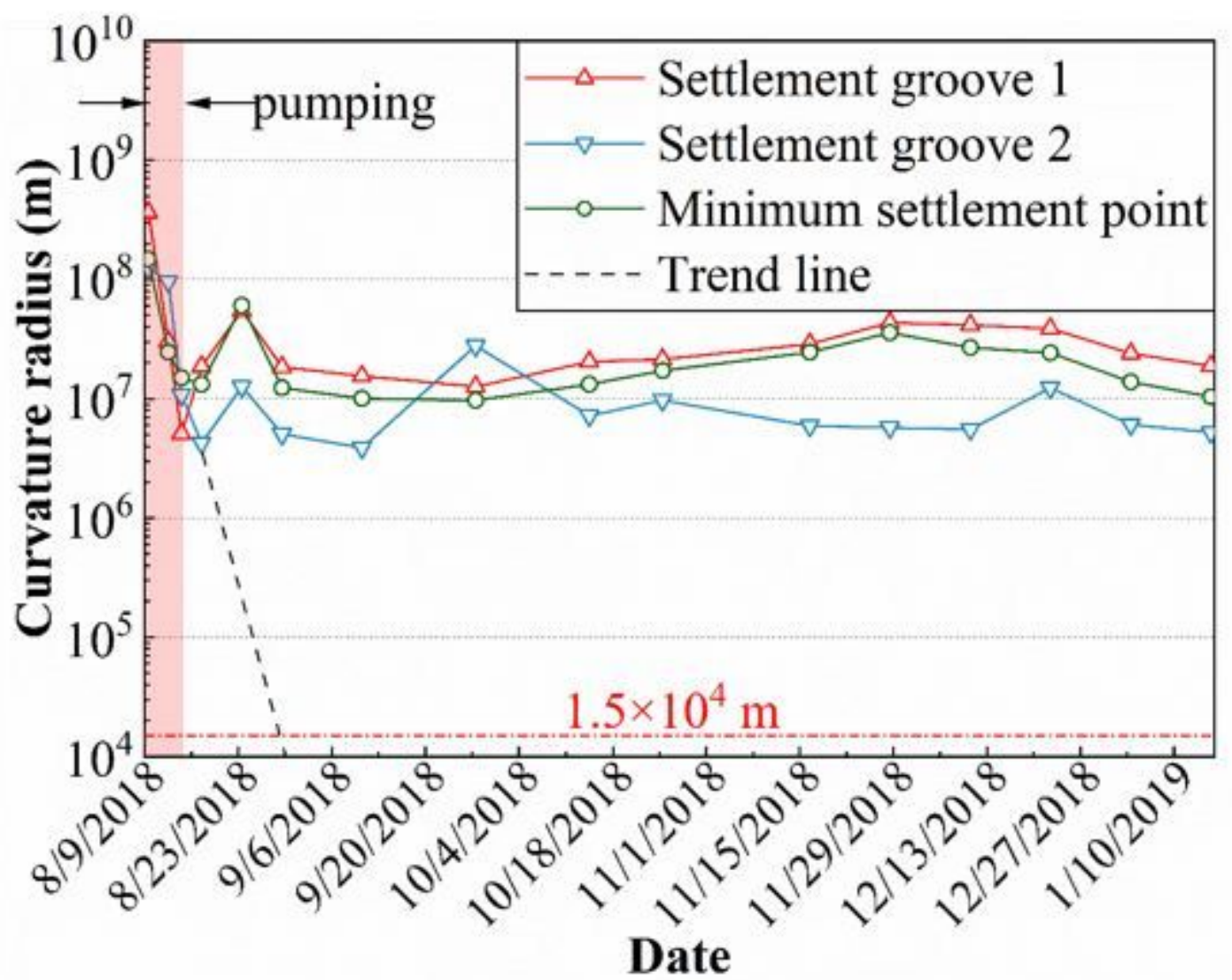

Figure 11

The minimum curvature radius of typical sections along the metro line. 